\title{
On the Reduction of a 3D CFD Combustion Model to Build a Physical OD Model for Simulating Heat Release, Knock and Pollutants in SI Engines
}

\author{
S. Richard, S. Bougrine, G. Font, F.-A. Lafossas and F. Le Berr \\ Institut français du pétrole, IFP, Direction Techniques d'Applications Énergétiques, \\ 1-4 avenue de Bois-Préau, 92852 Rueil-Malmaison Cedex - France \\ e-mail: stephane.richard@ifp.fr - sabre.bougrine@iff.fr - gregory.font@ifp.fr - falexandre.lafossas@iff.fr - fabrice.le-berr@ifp.fr
}

Résumé - Réduction d'un modèle de combustion 3D en vue d'obtenir un modèle $0 \mathrm{D}$ physique permettant de simuler le dégagement d'énergie, le cliquetis et les émissions de polluants des moteurs à allumage commandé - Actuellement, l'une des principales préoccupations de l'industrie automobile concerne la réduction progressive des émissions de polluants et de la consommation de carburant tout en améliorant les performances et l'agrément de conduite des véhicules. Pour satisfaire ces exigences, le moteur automobile a évolué en une dizaine d'années en un système très complexe combinant de nombreux composants de haute technologie avec des stratégies de contrôle très élaborées. L'optimisation et le contrôle de ce système sont alors devenus de véritables challenges pour les constructeurs automobiles. Dans ce contexte, les outils de simulation du groupe motopropulseur se sont démocratisés et peuvent aujourd'hui être utilisés à toutes les étapes de développement des moteurs, du choix de l'architecture au développement des stratégies de contrôle et à la calibration. Cependant, pour être efficaces, ces outils nécessitent des modèles sophistiqués, en particulier dans les cylindres où se produisent les processus de combustion et de formation de polluants. Ce papier présente un modèle $0 \mathrm{D}$ physique de combustion dédié à la prédiction du dégagement d'énergie, du cliquetis et des polluants dans les moteurs à allumage commandé. L'originalité du modèle réside dans le fait qu'il est basé sur la réduction du modèle de combustion 3D E-CFM (Extended Coherent Flame Model) développé à l'IFP. Le formalisme CFM distingue deux zones: les gaz frais et les gaz brûlés qui sont séparés par un front de flamme et sont entièrement décrits par leurs masse, température et composition. Le modèle $0 \mathrm{D}$ proposé dans ce travail est une évolution importante du modèle CFM-1D déjà publié. Il permet le calcul du taux de consommation des gaz frais en se basant sur la surface de flamme turbulente. Cette surface est calculée en utilisant un prétraitement géométrique de la chambre de combustion associé à une réduction de l'équation 3D pour la densité de surface de flamme. La formation du CO est calculée à la fois au travers du front de flamme et dans les gaz brûlés en utilisant un schéma cinétique réduit tandis que les NOx sont estimés par le modèle de Zel'dovitch étendu. Le calcul du délai de cliquetis est effectué dans la zone 'gaz frais' en décrivant l'évolution d'un précurseur d'auto-inflammation et une corrélation simple est utilisée pour estimer l'intensité du cliquetis correspondante. Le modèle complet est validé avec des données expérimentales concernant un ensemble de points de fonctionnement stabilisés d'un moteur monocylindre. Des variations paramétriques autour des réglages optimaux du moteur sont également réalisées. Un bon accord avec les expériences est observé, montrant l'intérêt de réduire les modèles de CFD 3D afin de construire des modèles $0 \mathrm{D}$ prédictifs pour la simulation du système moteur dans son ensemble. 


\begin{abstract}
On the Reduction of a 3D CFD Combustion Model to Build a Physical OD Model for Simulating Heat Release, Knock and Pollutants in SI Engines - In the automotive industry, today's major objectives concern the reduction of pollutant emissions and fuel consumption while improving performance and driveability. For this purpose, during the last decade, the classical engine has evolved towards a very complex system combining many hi-tech components with advanced control strategies. Optimizing the whole engine system and controlling its behaviour has then become a real challenge for car manufacturers. In this context, powertrain simulation tools have been shown to be an undisputable support during all stages of the engine development from concept design to control strategies development and calibration. However these tools require sophisticated models to be efficient, especially in the combustion chamber where combustion and pollutant formation processes take place. This paper presents a OD physical combustion model devoted to the prediction of heat release, knock and pollutants in SI engines. The originality of the model derives from the fact it is based on the reduction of the $3 D$ CFD E-CFM (Extended Coherent Flame Model) model developed at IFP. The CFM formalism distinguishes two zones: the fresh and the burnt gases, which are separated by a flame front and are both described by their temperature, mass and composition. The proposed model is an important evolution of the CFM-1D model previously published. It computes the rate of consumption of the fresh gases and is based on the calculation of the flame front surface using the real engine geometry and a OD derivation of the flame surface density approach. Pollutants (CO and NOx) are computed both through the flame front an within the burnt gases using a reduced kinetic scheme and a classical extended Zel'dovitch mechanism. The knock timing calculation is performed in the fresh gases zone describing the evolution of an auto-ignition precursor and a simple correlation is used to estimate the corresponding knock intensity. The whole model is validated against experimental data at several steady state operating points for a single-cylinder engine. Parametric variations around optimal engine settings are also performed. A good agreement with experiments is observed, showing the interest of reducing $3 D C F D$ models to build predictive OD models for engine system simulations.
\end{abstract}

\section{NOMENCLATURE}

$\begin{array}{ll}\text { SI } & \text { Spark Ignition } \\ \text { GDI } & \text { Gasoline Direct Injection } \\ \text { VCT } & \text { Variable Camshaft Timing } \\ \text { CAD } & \text { Crank Angle Degree } \\ \text { IVC } & \text { Intake Valves Closure } \\ \text { IVO } & \text { Intake Valves Opening } \\ \text { EVC } & \text { Exhaust Valves Closure } \\ \text { EVO } & \text { Exhaust Valves Opening } \\ \text { RPM } & \text { Revolutions Per Minute } \\ \text { IMEP } & \text { Indicated Mean Effective Pressure (bar) } \\ \text { FAR } & \text { Fuel Air (Equivalence) Ratio } \\ \text { SA } & \text { Spark Advance (CAD) } \\ \text { BMF } & \text { Fuel Burnt Mass Fraction } \\ \text { N } & \text { Engine speed (rpm) } \\ \text { BLSA } & \text { Borderline Spark Advance }\end{array}$

\section{INTRODUCTION}

In the two last decades, piston engines' specifications have greatly evolved. Indeed, main challenges nowadays concern the reduction of pollutant and $\mathrm{CO}_{2}$ emissions. To satisfy these new requirements, powertrains have become very complex systems combining many high technology components (high pressure injectors, 2-stage turbocharger, EGR loop, after-treatment devices, variable valve actuators, energy recovery and storage systems, etc.) with advanced control strategies. In the past, engine developments were mainly based on experiments using engine test benches. This approach is not adapted to the complexity of new engines: on the one hand, tests are very expensive and on the other hand they do not give enough information to permit the understanding of interactions between components. Today, a promising alternative to experimental tests may be the use of $0 \mathrm{D} / 1 \mathrm{D}$ simulation tools. These tools have known rapid improvements in the past ten years and can today be used at all stages of the engine development, from concept design to powertrain control development and calibration. However, they are generally based on empirical models [1,2] and often suffer from a lack of predictivity, especially when dealing with incylinder phenomena. A solution for extending the range of application of the system simulation consists of developing more physical models including a detailed description of combustion and pollutants formation processes. Such models can be obtained using $0 \mathrm{D}$ phenomenological approaches $[3,4]$ or reducing $3 \mathrm{D}$ CFD combustion models $[5,6]$. The second method is used in this work to derive a 0D physical combustion model dedicated to the prediction of heat release, knock and pollutant emissions in SI engines. 


\section{COMBUSTION MODELLING}

The model proposed in this paper is an important evolution of the CFM-1D model already presented in [5]. It includes a more precise approach for computing the turbulent flame surface evolution and describes the formation and evolution of pollutants in the cylinder. It is also coupled to a simple autoignition model to predict the onset of knock in the engine.

\subsection{Principle and Assumptions}

This work is based on the 3D CFD CFM model initially developed for RANS [7] and LES [8] calculations. The coherent flame model (CFM) is a combustion model dedicated to the flamelet regime. This approach is well adapted to premixed and partially premixed combustion processes, which represent the main oxidation mechanism in SI engines. As presented in Figure 1, the CFM formalism distinguishes two zones: fresh and burnt gases which are separated by a flame front propagating from the burnt gases towards the fresh mixture. Chemical reactions of fuel oxidation occurs in a very thin layer (the flame front) compared to all scales of the turbulent flow and post-flame chemistry takes place in the burnt gases.

The different equations of the model, initially written for 3D simulations, are reduced by integration over the cylinder to obtain a 0D physical model called the CFM-1D model as it accounts for the radial propagation of the flame. This reduction of the 3D model is based on several assumptions:

- The gaseous mixture consists of 15 species (Fuel, $\mathrm{N}_{2}, \mathrm{O}_{2}$, $\mathrm{H}_{2}, \mathrm{H}_{2} \mathrm{O}, \mathrm{CO}, \mathrm{CO}_{2}, \mathrm{NO}, \mathrm{NO}_{2}, \mathrm{HC}, \mathrm{NH}_{3}$, soot, $\left.\mathrm{O}, \mathrm{H}, \mathrm{OH}\right)$ considered as perfect gases.

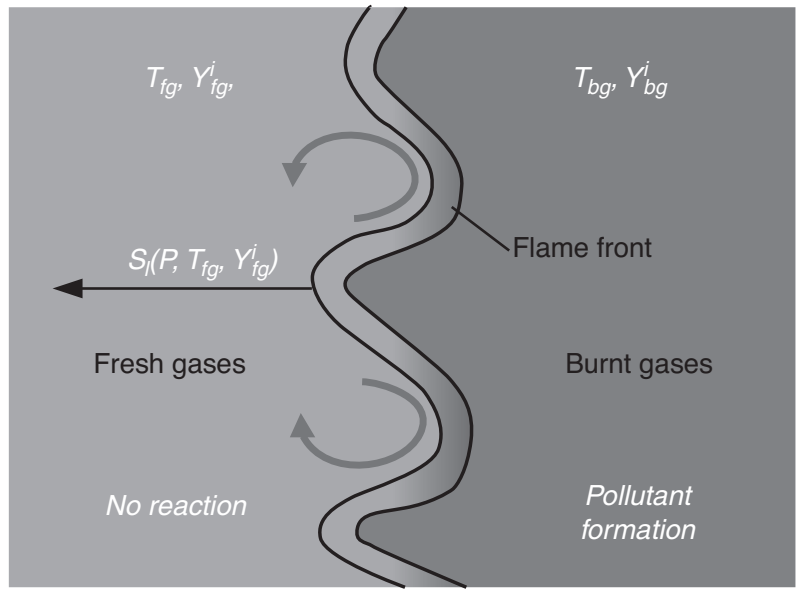

Figure 1

The coherent flame approach (subscripts $f g$ and $b g$ respectively refer to fresh and burnt gases).
- The mixture composition is considered as homogeneous in each zone (fresh and burnt gases).

- Fuel can be found in both liquid and gaseous phases in the combustion chamber. In this case, liquid fuel is treated as a separated thermodynamic system exchanging mass and enthalpy by vaporization with the fresh gases.

- The pressure is assumed to be the same in both zones.

- Each zone is described by its mass, volume, composition and temperature [7].

- The turbulent kinetic energy field is assumed to be uniform in the cylinder.

\subsection{Heat Release Calculation}

The enthalpy balance for the combustion chamber is:

$$
\frac{d m h}{d t}=V \frac{d P}{d t}+\frac{d Q_{\text {comb }}}{d t}-\frac{d Q_{\text {wall }}}{d t}+\sum_{\text {in,out }} h_{j} \frac{d m_{j}}{d t}
$$

where $V$ is the cylinder volume, $h$ is the mass enthalpy, $m$ is the enclosed mass and $P$ is the pressure which is linked to the mean temperature $T$ by the perfect gas law. The last term of Equation (1) refers to enthalpy exchanges at the inlets and outlets (valves, injector). $Q_{\text {wall }}$ corresponds to heat losses at the walls which are described with the Woschni model [9]. $Q_{\text {comb }}$ is the heat released by combustion processes and can be expressed as:

$$
\frac{d Q_{c o m b}}{d t}=\sum_{i} h_{f_{i}}\left(\left.\frac{d m_{i}}{d t}\right|_{f f}+\left.\frac{d m_{i}}{d t}\right|_{p f}\right)
$$

where $h_{f_{i}}$ is the formation enthalpy of specie $i, d m_{i \mid f f}$ and $d m_{i p f}$ are the mass variations of this specie respectively in the flame front and in the burnt gases due to post flame chemistry reactions. These variations are coupled with pollutant formation processes and will be detailed further in the paper. $d m_{i f f}$ can be expressed as a function of the fuel consumption rate:

$$
\left.\frac{d m_{i}}{d t}\right|_{f f}=\left.v_{i} \frac{W_{i}}{W_{f}} \frac{d m_{f u e l}}{d t}\right|_{f f}
$$

where $v_{i}$ is the stoichiometric coefficient of specie $i, W$ denotes the molecular weight and $\left.d m_{f u e l}\right|_{f}$ is defined as:

$$
\left.\frac{d m_{\text {fuel }}}{d t}\right|_{f f}=\left.\frac{d m_{\text {fuel }}^{f g}}{d t}\right|_{f f}-T_{\text {fuel }}^{f g \rightarrow b g}
$$

where $d m_{f u e l f f f}^{f g}$ is the fuel lost by the fresh gases zone through the flame and $T_{f u e l}^{f g \rightarrow b g}$ is the transfer of fuel from fresh to burnt gases in very rich cases.

In the CFM model, $\left.d m_{f u e l}^{f g}\right|_{f f}$ depends on the turbulent flame surface $S_{t}$ and the fresh gases properties:

$$
\left.\frac{d m_{\text {fuel }}^{f g}}{d t}\right|_{f f}=-\rho_{f g} Y_{\text {fuel }}^{f g} U_{l} S_{t}
$$


where $\rho_{f g}$ is the fresh gases density, $Y_{\text {fuel }}^{f g}=m_{\text {fuel }}^{f g} / \mathrm{m}_{f g}$ is the fuel mass fraction in the fresh gases and $U_{l}$ is the laminar flame speed computed with Metghalchi and Keck's correlation [10]:

$$
U_{l}=U_{l}^{0}\left(\frac{T_{f g}}{T^{0}}\right)^{\alpha}\left(\frac{P}{P^{0}}\right)^{\beta}\left(1-2.1 X_{r b g}\right)
$$

where $U_{l}^{0}$ is the reference laminar flame speed at $P^{0}$ and $T^{0}$, $\alpha$ and $\beta$ are coefficients depending on the fuel air equivalence ratio, $X_{r b g}$ is the molar fraction of residuals in the fresh gases and $T_{f g}$ is the fresh gases temperature.

The turbulent flame surface $S_{t}$ is written as the product of a mean surface $S_{m}$ and the flame front wrinkling $\Xi$ (Fig. 2):

$$
S_{t}=\Xi S_{m}
$$

Finally, the mass evolution of specie $i$ is:

$$
\begin{aligned}
& \frac{d m_{i}}{d t}=\left.\frac{d m_{i}}{d t}\right|_{\text {inlete exhaust }}+\left.\frac{d m_{i}}{d t}\right|_{f f}+\left.\frac{d m_{i}}{d t}\right|_{p f} \text { for } i \neq \text { fuel } \\
& \frac{d m_{\text {fuel }}}{d t}=\left.\frac{d m_{\text {fuel }}}{d t}\right|_{\text {inlet lexh }}+\left.\frac{d m_{\text {fuel }}}{d t}\right|_{\text {evap }}+\left.\frac{d m_{\text {fuel }}}{d t}\right|_{f f}+\left.\frac{d m_{\text {fuel }}}{d t}\right|_{p f}
\end{aligned}
$$

where $\left.d m_{\text {fuel }}\right|_{\text {evap }}$ is defined below.

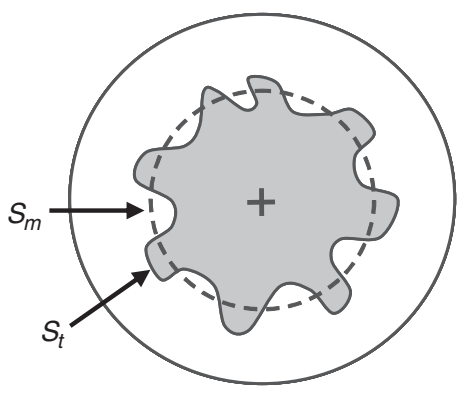

Figure 2

Definition of the mean and turbulent flame surfaces.

\subsubsection{Fresh and Burnt Gases Properties Computation}

The fresh gases composition at IVC is obtained from the fresh charge composition at the intake and the amount of residual burnt gases in the cylinder. The fresh gases mass then evolves due to combustion reactions in the flame front and to the injection of fuel when dealing with GDI engines. In this case, the rate of gaseous fuel production by evaporation is estimated as:

$$
\left.\frac{d m_{\text {fuel }}^{f g}}{d t}\right|_{\text {evap }}=\left.\frac{d m_{\text {fuel }}}{d t}\right|_{\text {evap }}=\frac{m_{\text {fuel }}^{\text {liq }}}{\tau}
$$

where $m_{\text {fuel }}^{\text {liq }}$ is the current mass of liquid fuel in the combustion chamber and $\tau=10^{-3} \mathrm{~s}$ is a time scale.

After IVC, the mass evolution of specie $i$ in the fresh gases can then be written as:

$$
\begin{aligned}
& \frac{d m_{i}^{f g}}{d t}=\left.\frac{d m_{\text {fuel }}^{f g}}{d t}\right|_{\text {ff }} \frac{m_{i}^{f g}}{m_{\text {fuel }}^{f g}} \\
& \frac{d m_{\text {fuel }}^{f g}}{d t}=\left.\frac{d m_{\text {fuel }}^{f g}}{d t}\right|_{f f}+\left.\frac{d m_{\text {fuel }}^{f g}}{d t}\right|_{\text {evap }}
\end{aligned}
$$

The fresh gases temperature $T_{f g}$ is obtained by inversion from the fresh gases composition and the fresh gases enthalpy $h_{f g}$ [5]. $h_{f g}$ is computed after IVC using a 0D equation reduced from the $3 \mathrm{D}$ balance equation for the fresh gases enthalpy $[7,11]$ :

$$
\frac{d m h_{f g}}{d t}=\frac{\rho}{\rho_{f g}} \frac{d P}{d t} V+\frac{d Q_{\text {wall }}^{f g}}{d t}
$$

The right hand side terms correspond respectively to the compression work and to heat transfer at the walls. $Q_{\text {wall }}^{f g}$ is computed with Woschni's correlation.

The fresh gases density is obtained from the fresh gases volume $V_{f g}$ and $m_{f g}: \rho_{f g}=m_{f g} / V_{f g} . V_{f g}$ can be computed with $P, T_{f g}$ and the fresh gases composition using the perfect gas law.

Following the CFM formalism, a progress variable $c$ is defined to account for the evolution of chemical reactions in the flame front:

$$
c=1-\frac{m_{f g}}{m}
$$

The burnt gases enthalpy can then be deduced from the mean and fresh gases enthalpies:

$m h=(1-c) m_{f g} h_{f g}+c m_{b g} h_{b g}$
where $m_{b g}=\sum_{i} m_{i}^{b g}$ and $m_{i}^{b g}=m_{i}-m_{i}^{f g}$

The burnt gases temperature $T_{b g}$ is deduced by inversion from the burnt gases composition and $h_{b g}$. Finally, the burnt gases volume $V_{b g}$ is written as: $V_{b g}=V-V_{f g}$.

The algorithm used to solve Equations (1) to (13) is presented in detail in [5].

\subsubsection{Mean Flame Surface Calculation}

The mean evolution of the flame surface over many engine cycles has been investigated by Baritaud [12]. These experiments suggest that the mean flame front grows spherically in the cylinder. $S_{m}$ is then computed assuming a spherical flame propagating from the spark plug position in a realistic geometry for the combustion chamber (Fig.3).

For this purpose, $S_{m}$ is a priori tabulated as a function of the piston position and the burnt gases volume (Fig. 4). The mean flame surface is then obtained at each time step by interpolation from the look-up table using the current piston 

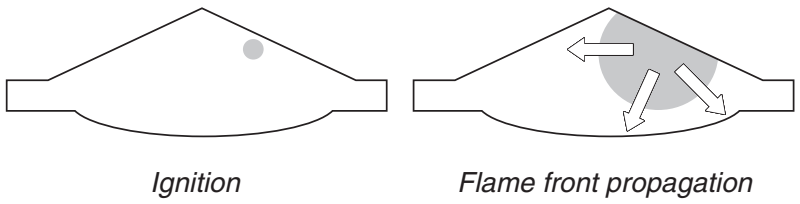

Figure 3

Mean flame surface evolution in a realistic combustion chamber.

position and burnt gases volume. This look-up table can be built with a 3D CAD software by computing intersections between the spherical enflamed volume and the combustion chamber walls to retrieve the enclosed flame surface $[13,14]$. However, as the 3D engine geometry is not always available, a pre-processing tool based on the main geometrical characteristics of the engine (bore, stroke, roof angle, bowl dimensions, compression ratio, spark plug position) has been developed in this work. This tool provides a slightly simplified engine geometry and can deal with pent-roof and flat cylinder heads as well as flat and bowled pistons. The tool then computes the mean flame surface in the same way as in [14].

\subsubsection{Flame front Wrinkling Computation}

A simple way to compute the flame wrinkling is the use of a classical Damköhler's formulation based on an equilibrium assumption for $\Xi[5,15]$ :

$$
\Xi=\Xi_{\text {equ }} g\left(r_{b g}\right)=\left(1+2 \frac{u^{\prime}}{U_{l}} \sqrt{\frac{\Gamma C}{S c}}\right) g\left(r_{b g}\right)
$$

where $u^{\prime}$ is the instantaneous velocity fluctuation, $\Gamma$ is the efficiency function of the turbulent flow on the flame strain

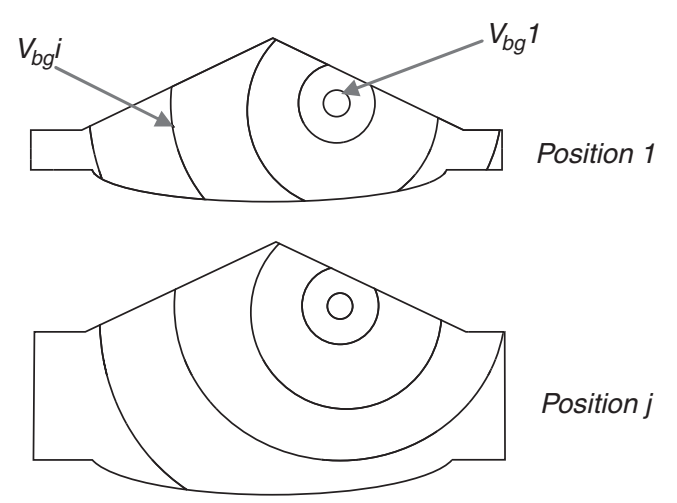

Figure 4

Principle of the mean flame surface tabulation.
[16], $C$ is a modelling constant, $S c$ is the Schmidt number, $r_{b g}$ is the current mean flame radius and $g$ a function accounting for the laminar-turbulent transition of the flame front. This approach is very close to those proposed in the literature which are commonly based on a fractal description of the flame front [3] combined with a phenomenological description of the transition from the laminar flame kernel to a fully developed turbulent flame front $[13,17]$.

The major drawback of a such model for the laminarturbulent transition is its lack of predictivity [13, 18]. Indeed, a tunable transition flame radius is often used to match experimental cylinder pressure curves. However, the transition process depends strongly on the current thermodynamic and flow conditions [12], thus the flame surface evolution is difficult to reproduce correctly for all engine operating conditions without modifying this radius. A promising alternative to this method can be the use of a physical equation for the temporal evolution of the flame wrinkling. This equation can be obtained by reduction of the 3D CFD equation for the flame surface density [8]:

$$
\begin{aligned}
\frac{1}{\Xi} \frac{d \Xi}{d t}= & \Gamma\left(u^{\prime} / U_{l}, l_{t} / \delta_{l}\right) \frac{u^{\prime}}{l_{t}}\left(\frac{\Xi_{e q u}-\Xi}{\Xi_{\text {equ }}-1}\right) \\
& -\frac{2}{r_{b g}}(1+\tau)(\Xi-1) U_{l}
\end{aligned}
$$

where $l_{t}$ is the integral length scale, $\tau=\left(\rho_{f g} / \rho_{b g}\right)$ is the thermal expansion rate, $r_{b g}=\left(3 V_{b g} / 4 \pi\right)^{1 / 3}$ is the current burnt gases mean radius and $\delta_{l}$ is the laminar flame thickness estimated using Blint's correlation [19]. The first RHS term of Equation (15) corresponds to the flame strain by all turbulent structures while the second describes the effect of the thermal expansion which limits the flame front wrinkling by imposing a positive curvature on the flame front.

\subsubsection{OD Turbulence Model}

It can be observed in Equation (15) that the flame development strongly depends on the turbulence characteristics $\left(u^{\prime}, l_{t}\right)$. These characteristics are very sensitive to the combustion chamber and intake pipes geometry and to the engine operating point. Therefore the reduction of a $3 \mathrm{D}$ turbulence model to build a OD physical model is not obvious and strong geometrical assumptions are generally made to close the unknown terms. For example, in the K-k 0-dimensional model [20], $l_{t}$ is assumed to be exactly the distance between the piston and the cylinder head. An adjustable parameter is then often incorporated to the turbulent kinetic energy production term to fit experimental results.

For these reasons, a simple phenomenological turbulence model [5] is retained in this work. This model is expected to be less predictive than a reduced one, but has the advantage of being easy to control while remaining based on physical quantities. In this model, $l_{t}$ is assumed to remain constant and 
equal to its value at spark timing during the whole combustion stroke, while the evolution of $u^{\prime}=\sqrt{2 / 3 k}$ is described by a $0 \mathrm{D}$ equation for the turbulent kinetic energy $k$ :

$$
k=C_{\text {turb }} \cdot \frac{E_{\text {kin,diss }}}{m}
$$

where $E_{\text {kin, diss }}$ is the dissipated kinetic energy and $C_{\text {turb }}=1$ is a modelling constant. $E_{k i n, \text { diss }}$ is computed using the kinetic energy in the combustion chamber $E_{k i n}$ as follows:

$$
\frac{d E_{k i n, d i s s}}{d t}=\frac{d E_{k i n}}{d t}-C_{d i s s} \cdot E_{k i n, d i s s}
$$

where $C_{\text {diss }}=150$ is a modelling constant. Finally, the evolution of the kinetic energy is obtained assuming a linear decrease of the tumble motion from the intake valve closure (IVC) to the top dead centre and using the following expression:

$$
\frac{d E_{\text {kin }}}{d t}=\frac{1}{8} \cdot m \cdot \omega_{\text {eng }}^{2} \cdot\left[L^{2} \cdot \frac{d N_{\text {tumble }}}{d t}+2 N_{\text {tumble }} \cdot L \frac{d L}{d t}\right]
$$

with $L$ the distance between the piston and the cylinder head and $\omega_{\text {eng }}$ the engine speed in rad. $\mathrm{s}^{-1} . N_{\text {tumble }}$ is the tumble number at IVC and corresponds to an initial condition for the compression stroke.

\subsection{Pollutants Formation Model}

As a first step towards pollutant emissions prediction, models for $\mathrm{CO}$ and $\mathrm{NO}$ creation based on the 3D ECFM approach $[7,11]$ have been developed. These models are presented below. Unburnt hydrocarbons modelling is still in development at IFP and will not be discussed in this paper.

\subsubsection{CO Formation and Oxidation}

In premixed combustion, $\mathrm{CO}$ can be created both through the flame and in the burnt gases. $\mathrm{CO}$ formation in the flame front mainly occurs in rich mixtures. In this case, instead of using a classical stoichiometric chemical reaction for the fuel oxidation, a set of two equations is used to account for $\mathrm{CO}$ and $\mathrm{H}_{2}$ production:

$$
\left\{\begin{array}{l}
\mathrm{C}_{x} \mathrm{H}_{y}+\left(x+\frac{y}{4}\right) \cdot \mathrm{O}_{2} \rightarrow x \cdot \mathrm{CO}_{2}+\frac{y}{2} \cdot \mathrm{H}_{2} \mathrm{O}, \quad \Phi<0.98 \\
\alpha_{1} \cdot\left(\mathrm{C}_{x} \mathrm{H}_{y}+\left(x+\frac{y}{4}\right) \cdot \mathrm{O}_{2} \rightarrow x \cdot \mathrm{CO}_{2}+\frac{y}{2} \cdot \mathrm{H}_{2} \mathrm{O}\right)+ \\
\left(1-\alpha_{1}\right) \cdot\left(\mathrm{C}_{x} \mathrm{H}_{y}+\frac{x}{2} \cdot \mathrm{O}_{2} \rightarrow x \cdot \mathrm{CO}+\frac{y}{2} \mathrm{H}_{2}\right) \quad \Phi \geq 0.98
\end{array}\right.
$$

These reactions are weighted using a parameter $\alpha_{1}$ which can be expressed considering the atomic conservation of $\mathrm{C}$, $\mathrm{H}$ and $\mathrm{O}$, as:

$$
\alpha_{1}=\left(0.98 \cdot \frac{4 x+y}{\Phi}-2 x\right) / 2 x+y
$$

If the fuel/air equivalence ratio $\Phi$ is equal to $0.98, \alpha_{1}$ is equal to 1 , and both equations of set (19) are equivalent. Then, if $\Phi$ increases, $\alpha_{1}$ decreases correspondingly and the amount of $\mathrm{CO}$ produced increases. This set of equations allows the definition of the stoichiometric coefficients $v_{i}$ used in Equation (3).

Due to the high level of the burnt gases temperature, chemical reactions influencing $\mathrm{CO}$ emissions also occur in this zone. Indeed, the burnt gases composition evolves towards chemical equilibrium concentrations. In order to account for this mechanism, an equilibrium scheme is adopted [21]:

$$
\left\{\begin{array}{l}
\mathrm{N}_{2} \leftrightarrow 2 \cdot \mathrm{N} \\
\mathrm{O}_{2} \leftrightarrow 2 \cdot \mathrm{O} \\
\mathrm{O}_{2}+2 \cdot \mathrm{CO} \leftrightarrow 2 \cdot \mathrm{CO}_{2} \\
\mathrm{H}_{2} \leftrightarrow 2 \cdot \mathrm{H} \\
\mathrm{O}_{2}+\mathrm{H}_{2} \leftrightarrow 2 \cdot \mathrm{OH} \\
\mathrm{O}_{2}+2 \cdot \mathrm{H}_{2} \mathrm{O} \leftrightarrow 4 \cdot \mathrm{OH}
\end{array}\right.
$$

This set of 6 equations is based on 10 species and must be completed by 4 conservation equations for $\mathrm{C}, \mathrm{O}, \mathrm{H}$ and $\mathrm{N}$ to be solved. Then, using a Newton method for the system inversion, the equilibrium concentration $[i]^{\text {equil }}$ of each specie $i$ can be computed. As this concentration is not reached instantaneously, a pseudo kinetics is used in the burnt gases as long as $T_{b g}>1700 \mathrm{~K}$ :

$$
\left.\frac{d m_{i}}{d t}\right|_{\text {equil }}=\frac{m_{i}^{\text {equil }}-m_{i}}{\tau_{\text {chem }}}
$$

where $\tau_{\text {chem }}$ is the time necessary to relax the current burnt gases composition towards the chemical equilibrium. Furthermore, chemical kinetics being strongly dependent on the temperature level, $\tau_{c h e m}$ is expressed as a linear function of the burnt gases temperature.

\subsubsection{NO Formation}

Nitrogen oxides are mainly produced at high temperature levels. NO formation is then only described in the burnt gases zone using an extended Zel'dovitch mechanism [22] based on a set of 3 reversible equations:

$$
\left\{\begin{array}{l}
\mathrm{N}_{2}+\mathrm{O} \leftrightarrow \mathrm{NO}+\mathrm{N} \\
\mathrm{O}_{2}+\mathrm{N} \leftrightarrow \mathrm{NO}+\mathrm{O} \\
\mathrm{OH}+\mathrm{N} \leftrightarrow \mathrm{H}+\mathrm{NO}
\end{array}\right.
$$

This system is solved using the kinetic constants $K_{i}$ of the different equations $i$, with indexes + for the forward direction and - for the reverse one. The evolution of NO is then computed as: 


$$
\begin{aligned}
\left.\frac{d[\mathrm{NO}]}{d t}\right|_{\text {Zel'dov }} & =K_{1}^{+}[\mathrm{O}]\left[\mathrm{N}_{2}\right]+K_{2}^{+}[\mathrm{N}]\left[\mathrm{O}_{2}\right]+K_{3}^{+}[\mathrm{N}][\mathrm{OH}] \\
& -K_{1}^{-}[\mathrm{NO}][\mathrm{N}]-K_{2}^{-}[\mathrm{NO}][\mathrm{O}]-K_{3}^{-}[\mathrm{NO}][\mathrm{H}]
\end{aligned}
$$

The evolution of $\mathrm{N}_{2}, \mathrm{O}_{2}, \mathrm{~N}, \mathrm{O}, \mathrm{H}$ and $\mathrm{OH}$ is also taken into account using set (23). Kinetic constants $K_{i}$ are taken from [22] and defined in Table 1. This set of constants is only valid for temperatures higher than $2200 \mathrm{~K}$. Moreover, reactions of $\mathrm{NO}$ formation are known to be rapidly frozen during the expansion stroke [22]. Consequently, in this work, the Zel'dovitch mechanism is only solved for $T_{b g}>2500 \mathrm{~K}$.

TABLE 1

Kinetic coefficients for NO formation

\begin{tabular}{c|l|c}
\hline Coeff. & \multicolumn{1}{|c|}{ Value $\left(\mathrm{cm}^{3} / \mathrm{mol} . \mathrm{s}\right)$} & $\begin{array}{c}\text { Temperature } \\
\text { range }(\mathrm{K})\end{array}$ \\
\hline$K_{1}^{+}$ & $7.6 \times 10^{13} \exp \left[-38000 / T_{b g}\right]$ & $2000-5000$ \\
$K_{1}^{-}$ & $1.6 \times 10^{13}$ & $300-5000$ \\
\hline$K_{2}^{+}$ & $6.4 \times 10^{9} T_{b g} \exp \left[-3150 / T_{b g}\right]$ & $300-3000$ \\
$K_{2}^{-}$ & $1.5 \times 10^{9} T_{b g} \exp \left[-19500 / T_{b g}\right]$ & $1000-3000$ \\
\hline$K_{3}^{+}$ & $4.1 \times 10^{13}$ & $300-2500$ \\
$K_{3}^{-}$ & $2.0 \times 10^{14} \exp \left[-23650 / T_{b g}\right]$ & $2200-4500$ \\
\hline
\end{tabular}

Finally, the mass evolution of the species due to post flame chemistry reactions in the burnt gases is:

$$
\left.\frac{d m_{i}}{d t}\right|_{p f}=\left.\frac{d m_{i}}{d t}\right|_{\text {equil }}+\left.\frac{d m_{i}}{d t}\right|_{\text {Zel'dov }}
$$

\subsection{Knock modelling}

During spark ignition engines operation, spontaneous autoignition of fresh gases pockets can occur before the arrival of the flame front. This phenomenon, known as knock, produces a distinctive noise and is characterised by a rapid rise of the energy release, pressure and heat transfer in the cylinder. When persisting, this uncontrolled combustion process can even lead to serious mechanical and thermal damages.

Knock is known to be very sensitive to the fresh gases composition and temperature. Its occurrence can be prevented by limiting the compression ratio, the spark advance or the boost level when dealing with supercharged engines. However, these solutions have a negative impact on the engine performances and thermodynamic efficiency. Optimizing the engine behaviour from its initial design to its control strategies development can then not be performed without predicting the onset of knock.

\subsubsection{Knock Timing Calculation}

Knock timing is computed as in the 3D ECFM model using a simple $A n B$ expression to estimate the instantaneous auto-ignition delay $\theta$ [23]. This formulation is based on an Arrhenius law and accounts for the research octane number $(R O N)$ of the fuel, the fuel/air equivalence ratio $\Phi$, the residual burnt gases molar fraction in the fresh gases zone $X_{r b g}$, the pressure $P$ and temperature of the fresh gases $T_{f g}$ :

$$
\theta=A\left(\frac{R O N_{e f f}}{100}\right)^{3.402} P_{e f f}{ }^{-n} e^{\left(\frac{B}{T_{f g}}\right)}
$$

where $R O N_{\text {eff }}=R O N e\left(0.1 K_{f a r}(\Phi-1)^{2}\right), P_{e f f}=\frac{P}{1+K_{r b g} X_{r b g}}$, and $A, n, B$ are modelling constants (Tab. 2).

TABLE 2

Default parameters of the Arrhenius law used for the auto-ignition delay calculation

\begin{tabular}{c|c}
\hline$A$ & $0.01931 \mathrm{~s}$ \\
\hline$n$ & 1.7 \\
\hline$B$ & $3800 \mathrm{~K}$ \\
\hline$K_{f a r}$ & 1 \\
\hline$K_{r b g}$ & 10 \\
\hline
\end{tabular}

The proposed delay expression has the advantage of being low CPU consuming while providing results close to those obtained by complex chemistry calculations for a large range of operating conditions (Fig. 5).

During the compression and combustion strokes, thermodynamic conditions strongly evolve so that the knock delay can not be given directly by Equation (26). For this purpose, a model describing the evolution of an auto-ignition precursor is used [23]. This precursor $P$ is described by its mass fraction in the fresh gases which can be computed as:

$$
\frac{d Y_{p}}{d t}=Y_{\text {fuel }}^{0} F(\theta)
$$

where $Y_{\text {fuel }}^{0}=m_{\text {fuel }}^{0} / m_{f g}^{0}$ is the fuel mass fraction in the fresh gases before the start of the combustion and $F(\theta)$ is a function of the delay:

$$
F(\theta)=\frac{\sqrt{\alpha^{2} \theta^{2}+4(1-\alpha \theta) \frac{Y_{p}}{Y_{\text {fuel }}^{0}}}}{\theta}
$$

where $\alpha=1 \mathrm{~s}^{-1}$ is a constant. When $Y_{P}=Y_{\text {fuel }}^{0}$, auto-ignition occurs and the corresponding knock intensity is computed.

\subsubsection{Knock Intensity Estimation}

The quantification of knock intensity has enjoyed a great attention in the research literature and many different ways to estimate it have been proposed [25-30]. The first one consists in simulating the auto-ignition process itself, using reduced or detailed chemical schemes to compute the corresponding 

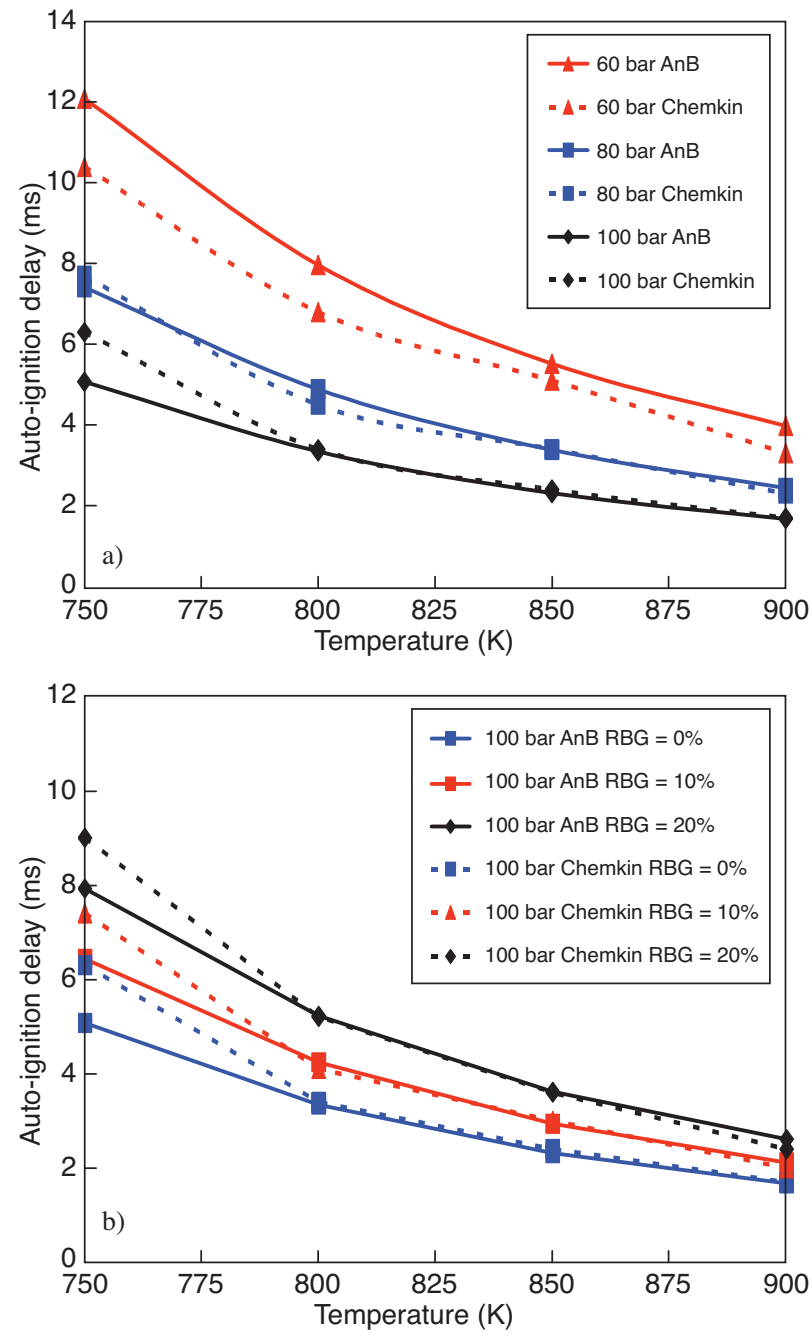

Figure 5

Comparisons between results from the $A n B$ model and complex chemistry calculations (chemical scheme from DCPR -500 species and 2500 reactions [24]):

a) Delay evolution for different pressures and temperatures and no residual burnt gases;

b) Delay evolution for different residual burnt gases rates at 100 bars.

heat release rate (HRR) [26-29]. In this case, a knock intensity should then be calculated from the cylinder pressure or the HRR signal following the same procedure as in experiments. However, using OD models, it is not obvious to have a fine prediction of the heat release rate for a wide range of operating conditions as knock is strongly dependent of the temperature, fuel and residual burnt gases distribution in the combustion chamber [31]. Moreover, for engineering applications, accounting for the influence of auto-ignition processes on the cylinder pressure evolution or the engine work is not of primary importance. What engineers want to know is the degree of spark retard required to avoid severe knock. For this reason, the heat release rate due to knock is not taken into account in this work and knock intensity is simply computed using a correlation. The idea of using a criterion for knock onset has been proposed in previous publications [25-30]. This criterion $K_{n}$ is generally based on the energy released by spontaneous auto-ignition of the remaining fresh charge at knock timing normalized by the total energy to be released by combustion through flame propagation. $K_{n}$ can then be written as:

$$
K_{n}=\frac{m_{\text {fuel }}^{f g}}{m_{\text {fuel }}^{0}}=1-b m f
$$

This formulation has to be corrected in rich cases as combustion may not be complete: $K_{n}=1-b m f \cdot \max (1, \phi)$. Some authors [25-30] also propose to account for the influence of the cylinder volume at the instant of knock occurrence. For this purpose, we propose here a correction based on the compression ratio $\Pi$ and the knock phasing in the expansion stroke $\theta_{\text {knock }}$ :

$$
K_{n}=(1-b m f \cdot \max (1, \phi))(\Pi-1) \sqrt{1-\frac{\theta_{k n o c k}}{K_{2}}}
$$

$K_{2}$ corresponds to the maximum crank angle for which knock is still audible and is generally set to $40-50 \mathrm{cad}$.

Finally, it is important to note that knock limited spark advances are often tuned for a given temporal frequency at the engine bench. Then knock margin is not the same at every engine speed and is higher at high rpm levels. Therefore, assuming that knock intensity is directly linked to the knock cyclic frequency, the indicator of Equation (30) can be considered as an image of this frequency. To compare the proposed knock indicator to the experimental one, the engine speed $N_{\text {eng }}$ should then be taken into account:

$$
K_{n}=K_{1}(1-b m f \cdot \max (1, \phi))(\Pi-1) \sqrt{1-\frac{\theta_{\text {knock }}}{K_{2}}} N_{\text {eng }}
$$

where $K_{1}$ is a parameter for tuning the global knock intensity level and expressed in $\mathrm{rpm}^{-1}$. Using Equation (31), four levels of intensity are distinguished:

- $K_{n}<0.5$ : no knock,

$-0.5 \leq K_{n}<1$ : trace knock,

$-1 \leq K_{n}<1.5$ : medium knock,

$-1.5 \leq K_{n}$ : strong knock.

\section{MODEL VALIDATION}

The combustion model proposed in this paper has been implemented in the AMESim ${ }^{\circledR}$ simulation software $[18,32]$. It has then been used to simulate many steady state operating points of a GDI single cylinder prototype. Experimental data were used for the boundary conditions (pressure, temperature) 


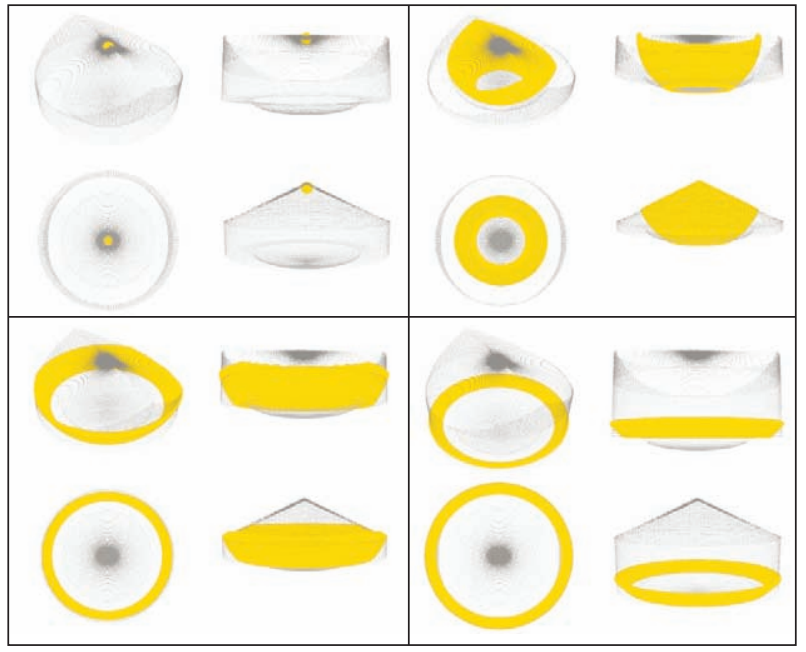

Figure 6

Simplified engine geometry obtained using the developed pre-processing tool for different burnt gases volumes and piston positions.

and the engine settings (spark advance, injection timing and duration). The main characteristics of the single cylinder engine are summarized in Table 3 and the simplified geometry obtained from the pre-processing tool is presented in Figure 6.

TABLE 3

Single cylinder engine characteristics

\begin{tabular}{l|c}
\hline Bore $(\mathrm{mm})$ & 69 \\
\hline Stroke $(\mathrm{mm})$ & 80.5 \\
\hline Compression ratio & 9.5 \\
\hline Connecting-rod length $(\mathrm{mm})$ & 139 \\
\hline
\end{tabular}

\subsection{Cylinder Pressure and Engine Work}

\subsubsection{Calibration Process Methodology}

The proposed CFM-1D combustion model is based on the reduction of 3D CFD equations and on weak assumptions for the mean flame geometry. It is thus expected to give an accurate description of physical processes without modifying any combustion parameter. Hence, only the turbulence model parameters $\left(N_{\text {tumble }}\right.$ at IVC and $l_{t}$ ) are adjusted to obtain a correct description of the flame front evolution and to match the experimental cylinder pressure curve. These parameters are then tabulated as a function of the volumetric efficiency and the engine speed and can be re-used to simulate transient operating conditions $[5,18,32]$.
The engine model used in this study is presented in Figure 7. The calculation time for a whole engine cycle was about $1 \mathrm{~s}$ and 57 operating points covering nearly the entire engine operating range were simulated (engine speed from 1000 to $5500 \mathrm{rpm}$ and IMEP from 2.5 to 30 bars).

The turbulence parameters $N_{\text {tumble }}$ and $l_{t}$ were adjusted using an automatic calibration tool, IFP-Optilab. This tool performs a sequence of runs with AMESim ${ }^{\circledR}$ for each operating point and uses optimization methods to minimize differences between experimental and simulated cylinder pressure curves. As IFP-Optilab is dedicated to the combustion stroke calibration, calculations begin at IVC (245 CAD) and end at EVO (475 CAD). Then, an accurate estimation of initial conditions is required to obtain a correct behaviour of the models. These conditions concern the mass fractions of air, fuel and residual burnt gases $\left(Y_{\text {air }}^{I V C}, Y_{\text {fuel }}^{I V C}, Y_{r b g}^{I V C}\right)$ and the mean temperature $T^{I V C}$ and mean pressure $P^{I V C}$ in the cylinder at IVC. Mass fractions of air and fuel are computed using the measured mass flow rates. However, air or fuel included in residual gases $(\mathrm{rg})$ from the previous engine cycle should not be forgotten, especially if the mixture is not stoichiometric. Moreover, burnt gases contained in residuals have a huge influence on combustion processes (heat release rate, knock, pollutants). Consequently, the residual gas mass fraction at IVC $Y_{r g}^{I V C}$ has to be precisely estimated to obtain reasonable values for the initial mass fractions of fuel, air and burnt gases. For this purpose, a two step procedure is followed for the model calibration (Fig. 8).

\section{First step}

For each operating point, $Y_{r g}^{I V C}$ is computed using an iterative procedure which stops when convergence is reached

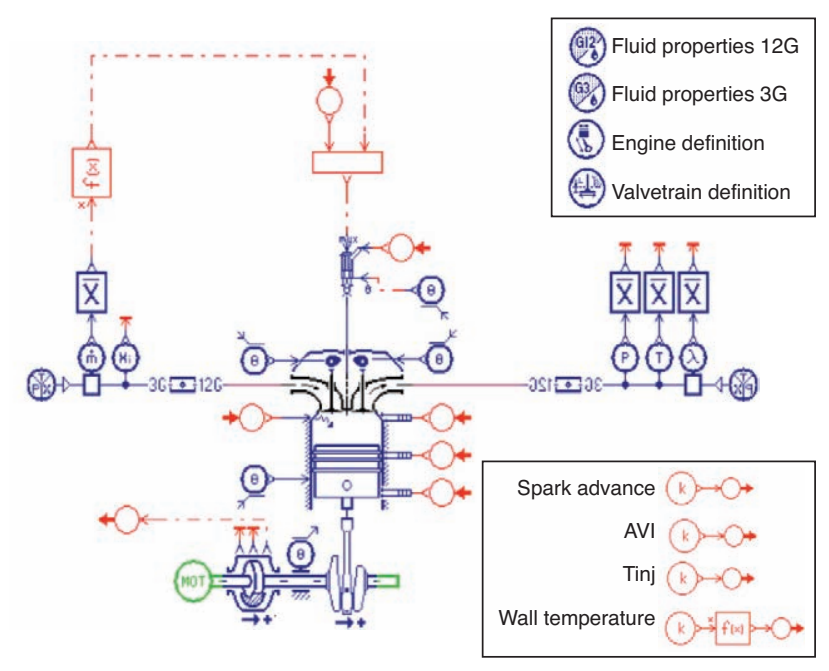

Figure 7

Presentation of the single cylinder engine model. 


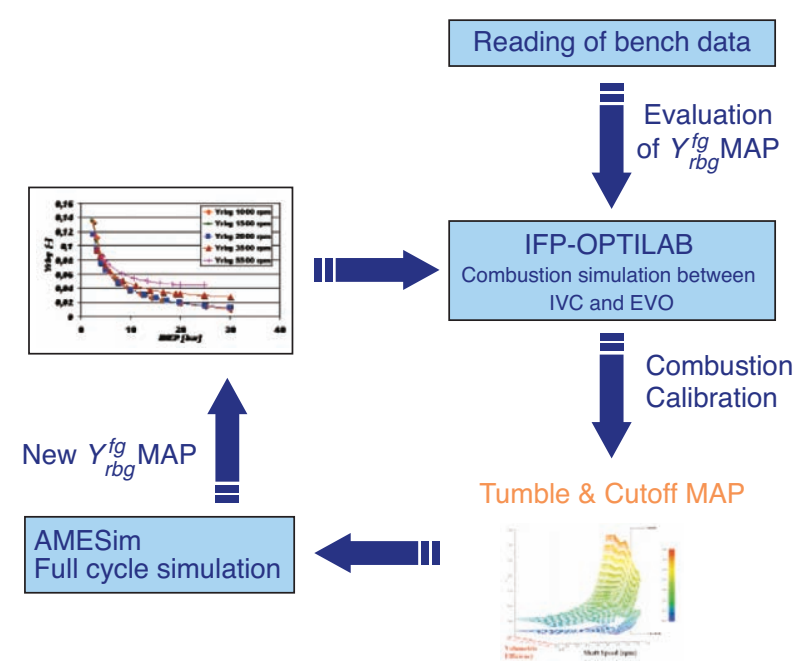

Figure 8

Combustion model calibration procedure.

$\left(Y_{r g}^{I V C^{n}}-Y_{r g}^{I V C^{n-1}}<10^{-9}\right)$. First, the residual gas temperature at IVO $T_{r g}^{I V O}$ is calculated assuming an adiabatic expansion of the residual burnt gases at intake valve opening:

$$
\frac{T_{r g}^{I V O}}{T_{r g}^{E V C}}=\left(\frac{P^{E V C}}{P^{I V O}}\right)^{\frac{\gamma-1}{\gamma}}
$$

$P^{I V O}, P^{E V C}$ and $T_{r g}^{E V C}$ are provided by the engine bench and are assumed to be equal to the intake pressure at IVO, exhaust pressure at EVC and exhaust mean temperature respectively. $T^{I V C}$ is then computed following:

$$
\begin{aligned}
\underbrace{h\left(T^{I V C}, Y_{i}^{I V C}\right)}_{\text {mixture at IVC }}= & \underbrace{Y_{r g}^{I V C^{n-1}} \cdot h\left(T_{r g}^{I V O}, Y_{i}^{I V O}\right)}_{\text {residual gases }} \\
& +\underbrace{\left(1-Y_{r g}^{I V C^{n-1}}\right) \cdot h\left(T_{\text {intake }}, Y_{i}^{\text {intake }}\right)}_{\text {fresh charge }}
\end{aligned}
$$

where $h$ is the sensible enthalpy, $Y_{r g}^{I V C^{n-1}}$ is the residual gas mass fraction at iteration $n-1$ and subscript $i$ denotes either air, fuel or burnt gases. The intake temperature $T_{\text {intake }}$ and composition $Y_{i}^{\text {intake }}$ are given by experiments, while compositions at IVC $Y_{i}^{I V C}$ and at IVO $Y_{i}^{I V O}$ are calculated using the intake composition and residuals mass fraction at iteration $n-1$. The enclosed mass at IVC $m_{I V C}$ is then:

$$
m_{I V C}=\frac{P^{I V C} V^{I V C}}{r^{I V C} T^{I V C}}
$$

where $V^{I V C}$ is the cylinder volume at IVC and where the mixture constant at IVC $r_{I V C}$ is estimated from the composition at IVC at iteration $n-1$ :

$$
r_{I V C}=Y_{\text {air }}^{I V C} \cdot r_{\text {air }}+Y_{\text {fuel }}^{I V C} \cdot r_{f u e l}+Y_{r b g}^{I V C} \cdot r_{r b g}
$$

Finally, the residual gas mass fraction at iteration $n, Y_{r g}^{I V C}{ }^{n}$, is given by the perfect gas law at EVC:

$$
Y_{r g}^{I V C^{n}} m_{I V C}=\frac{P^{E V C} V^{E V C}}{r_{r g} T^{E V C}}
$$

where $V^{E V C}$ is the cylinder volume at EVC and $r_{r g}$ is estimated using the residual composition at iteration $n-1$.

A first calibration is then performed with IFP-Optilab to build maps for the tumble number and the integral length scale.

\section{Second step}

In order to get a finer estimation of $Y_{r g}^{I V C}$, multi-cycle simulations are performed on the single cylinder engine model using maps for $N_{\text {tumble }}$ and $l_{t}$ from the first step. When convergence is reached for $Y_{r g}^{I V C}$, i.e. after approximately 5 cycles, the calculation is stopped. The residual gases mass fractions, pressure and temperature at IVC obtained from these simulations are then reused as initial conditions in IFPOptilab for a second calibration of the combustion model (Fig. 8). Differences between $Y_{r b g}^{I V C}$ computed in both steps are almost the same for all engine speeds and are presented in Figure 9 for $N=3500 \mathrm{rpm}$. It is shown that the residual gas mass fraction at IVC is larger at low load when using the multi-cycle simulation. This is because the backflow phenomenon occurring at IVO is neglected in the first step, while it is taken into account in the second step. These results then show the advantage of using a two-step procedure to obtain reliable initial conditions for the combustion model calibration.

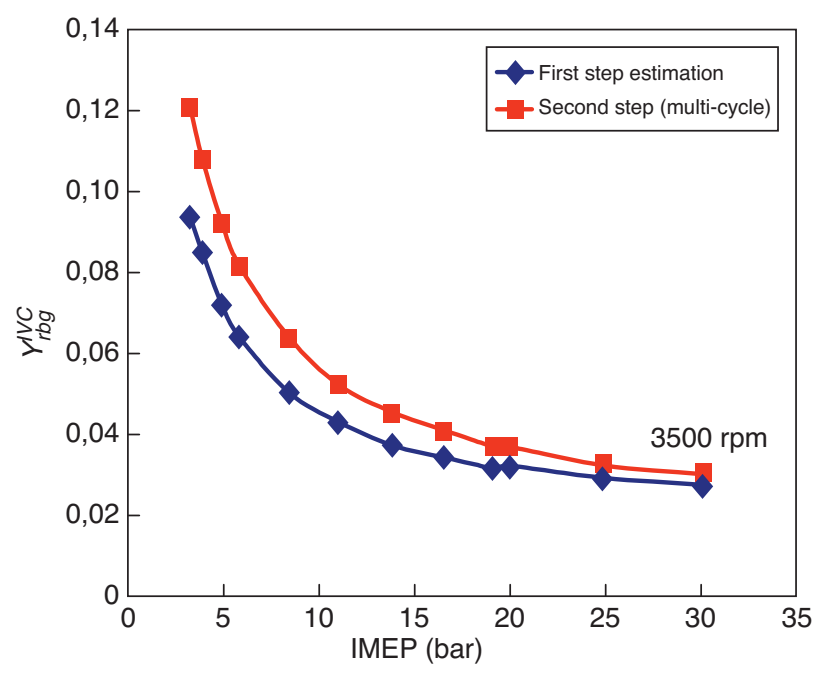

Figure 9

Comparison between $Y_{r b g}^{I V C}$ evaluated in the first step and $Y_{r b g}^{I V C}$ simulated in the second step. 


\subsubsection{Simulation Results}

First simulations concern optimal engine settings for 57 points (Fig. 10) covering a large range of operating conditions and for which experimental data were available.

Examples of simulated cylinder pressure curves are presented in Figure 11. Uncertainties about the real compression ratio and measured air mass flow rate on this experimental configuration leads to small errors in the compression stroke, especially at high engine speed. For example, the simulated cylinder pressure is underestimated at high load and $5500 \mathrm{rpm}$. However, results from simulations are globally in good agreement with experimental data, showing that the evolution of the heat release rate is described well for all operating conditions. In particular the maximum cylinder pressure level is correctly reproduced (Fig. 12) with relative errors less than $1 \%$ for $90 \%$ of the simulated points. Similarly, good precision is obtained on the IMEP with absolute errors below 0.3 bar for $90 \%$ of the points. Moreover, the largest errors on the IMEP are only found at high load, where they do not have any considerable influence on the simulated engine torque.

The maps obtained for the tumble number and the integral length scale are presented in Figure 13. It is encouraging to note that the evolution of these variables is smooth when varying the load or the engine speed. It should therefore be possible to obtain reasonable values of $N_{\text {tumble }}$ and $l_{t}$ by interpolation of data in look-up tables, for simulating transient engine operations. It is also interesting to note that the integral length scale decreases with the IMEP. As the spark

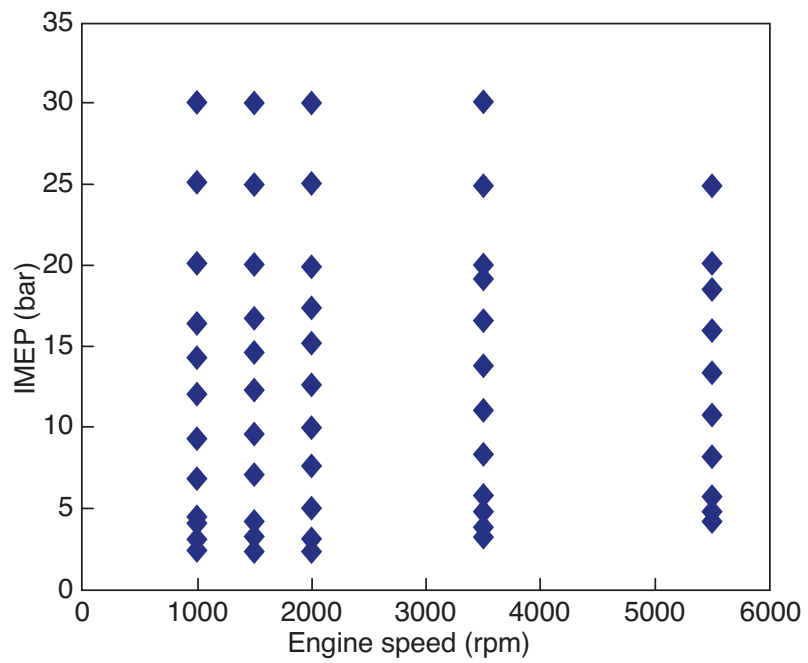

Figure 10

Presentation of the 57 steady state operating points used in the combustion model calibration process.

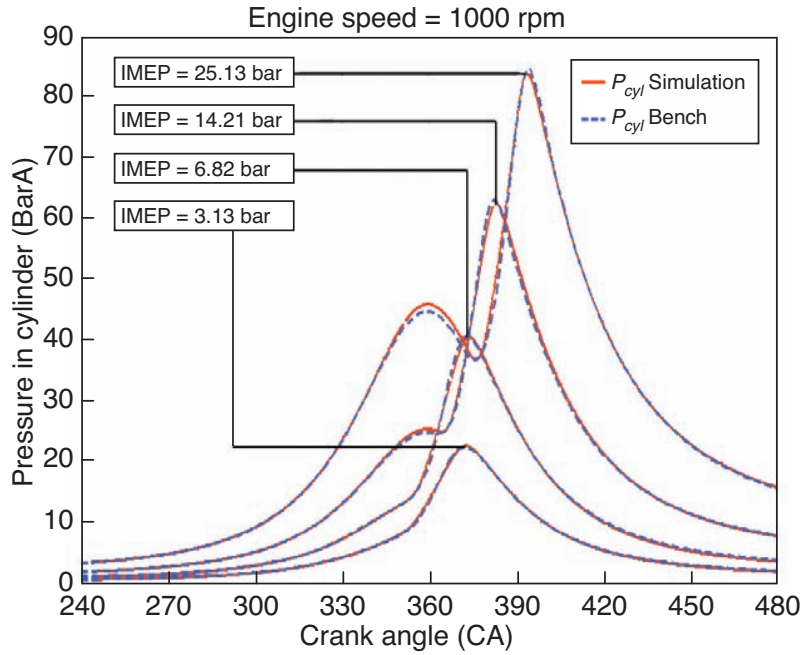

a)

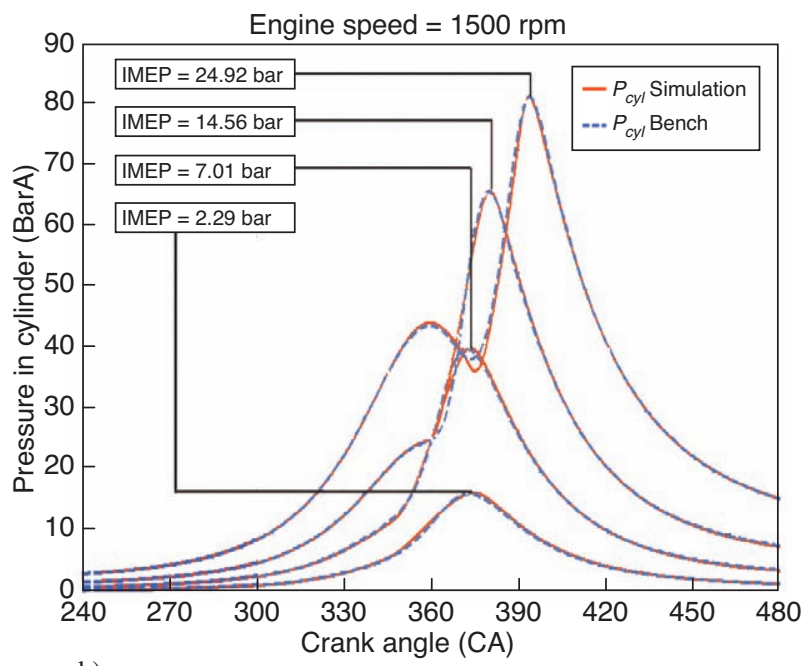

b)

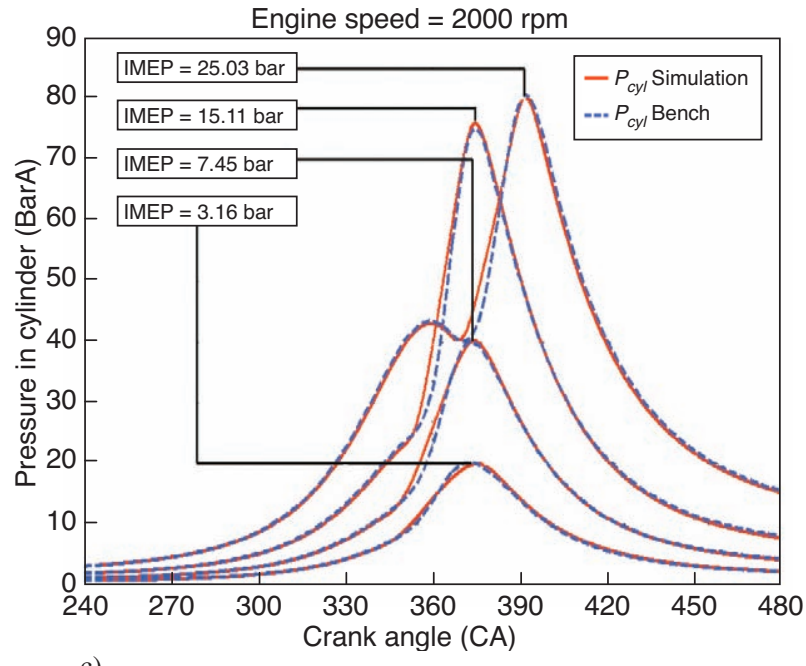

c)

Figure 11a, b, c

Comparison between experimental and simulated cylinder pressure curves for different operating points. 

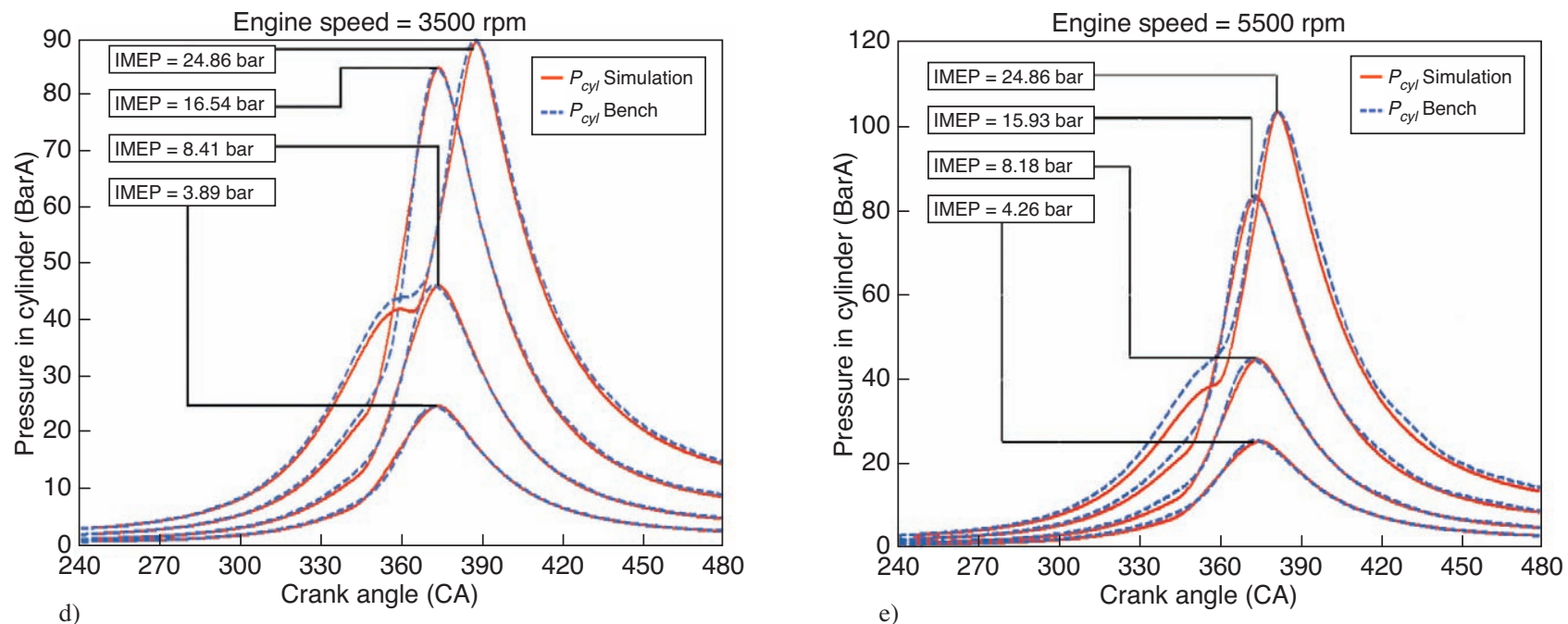

Figure 11d, e

Comparison between experimental and simulated cylinder pressure curves for different operating points.
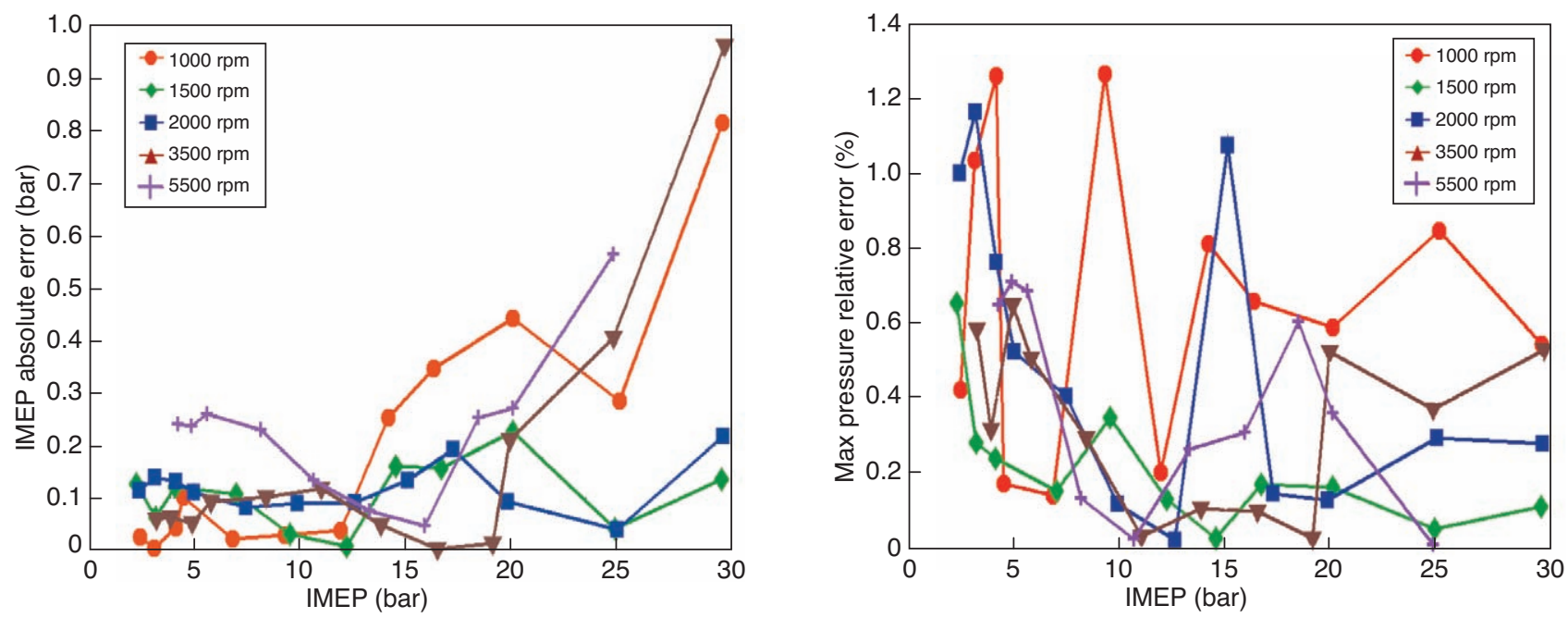

Figure 12

Errors on the IMEP and the maximum cylinder pressure level from the simulations.

advance is also reduced when increasing the engine load and as $l_{t}$ represents the integral length scale at spark timing, this means that $l_{t}$ evolves as expected theoretically: it decreases with the piston-cylinder head distance.

In order to check the behaviour of the modelling approach, spark advance variations around optimal settings also called reference settings - provided by the engine bench have been simulated. Unfortunately, no experimental data were available for the comparison with calculations. However, these variations concern operating points not limited by knock and for which trends are well known. The results obtained are almost the same for all engine speeds and are presented in Figures 14 and 16 for $N_{\text {eng }}=3500 \mathrm{rpm}$. As expected, the maximum pressure level increases with the spark advance and a bell curve is obtained for the IMEP. The maximum of this bell curve should be exactly located at the reference spark advance $(\mathrm{dSA}=0)$, corresponding to the experimental SA, if the turbulence model was perfectly predictive.

Indeed, the combustion heat release depends on the turbulent flame surface evolution which is mainly controlled by the turbulence level after ignition. Then the cylinder pressure and IMEP prediction are strongly influenced by the turbulence intensity found at spark timing. Depending on the load, it can be observed in Figure 14 that an error ranging from 0 to 3 crank angle degrees is obtained on the best spark advance timing (BSAT) for $N=3500 \mathrm{rpm}$. This error does not exceed $10 \mathrm{CAD}$ on the whole engine operating map 

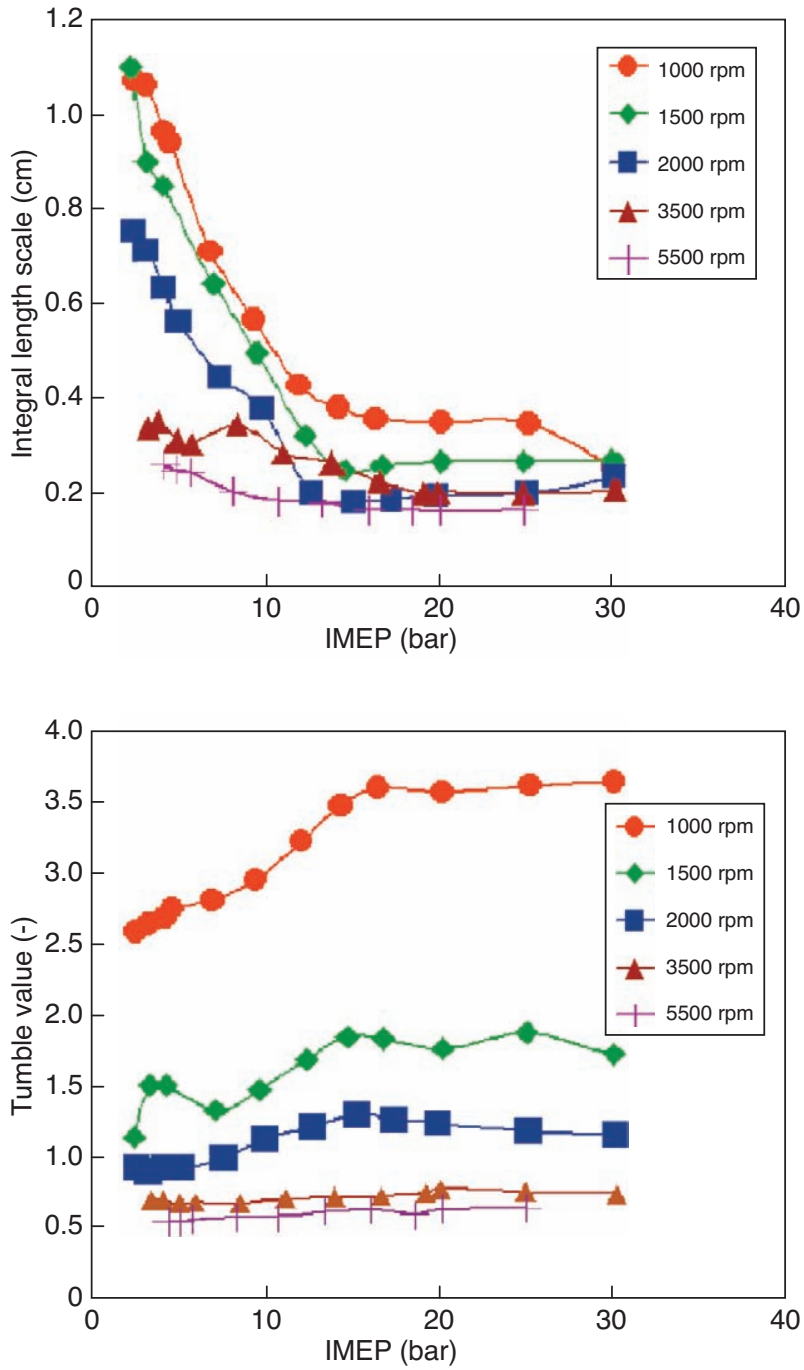

Figure 13

$N_{\text {tumble }}$ and $l_{t}$ maps obtained from the automatic calibration tool.

(Fig. 15) and is less than 5 CAD for $95 \%$ of the points. Considering the relative simplicity of the turbulence model used in this work, these results are satisfactory.

The influence of spark timing on the exhaust temperature is presented in Figure 16 for $N_{\text {eng }}=3500 \mathrm{rpm}$. A correct trend is obtained with an increase of the temperature level when decreasing the spark advance. This is due to the fact that the main part of the fuel is burnt in the expansion stroke, so that heat losses at the walls and energy transferred to the piston are smaller.

Most of the operating points from the engine map have been set with a unity fuel-air equivalence ratio (FAR). However, in real conditions, the engine can run with nonunity FAR, especially during transients. Hence, it is crucial to have a good behaviour of the combustion model when varying the FAR. All the points have then been simulated with FAR ranging from 0.6 to 1.3. Once again, trends are the same at all engine speeds and results are shown in Figures 17 and 18 for $N_{\text {eng }}=3500 \mathrm{rpm}$. A high increase of the IMEP is correctly observed for FAR from 0.6 to 1 as more and more energy is released by combustion processes. On the contrary, the IMEP tends to decrease slightly on the rich side with a maximum value situated around FAR $=1.1$, which is known to be the fuel air ratio corresponding to maximum engine power. This is due to reactions of dissociation at high temperature involving $\mathrm{CO}$ and $\mathrm{CO}_{2}$. These reactions allow to free a small amount of oxygen atoms which can be reused in the burnt gases to oxidize a part of the exceeding fuel.
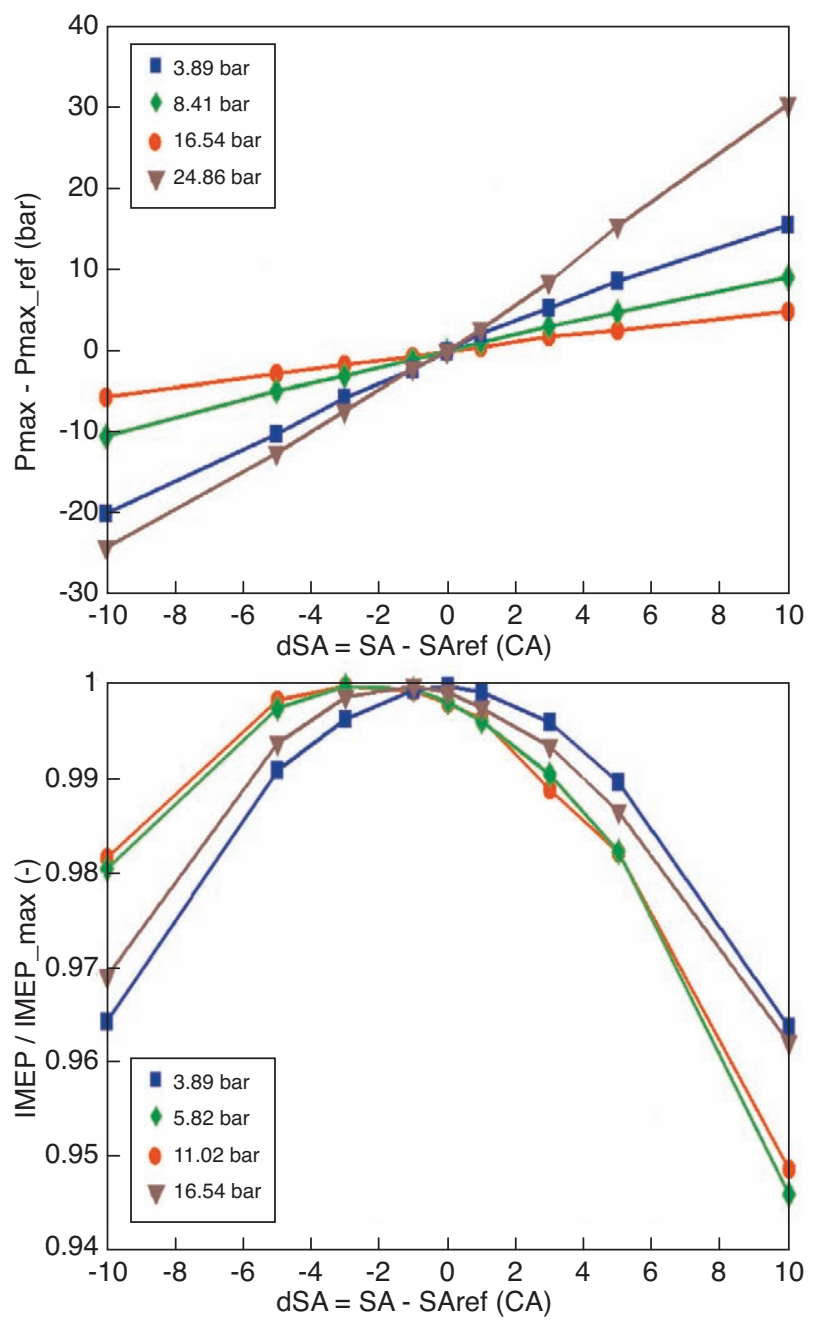

Figure 14

Spark advance variation around optimal engine settings at $3500 \mathrm{rpm}$ for different loads (results from simulations): top differences between the maximum pressure levels at the optimal spark advance (SAref) and at spark advance SA, bottom - differences between the maximum IMEP and the IMEP at spark advance SA. 


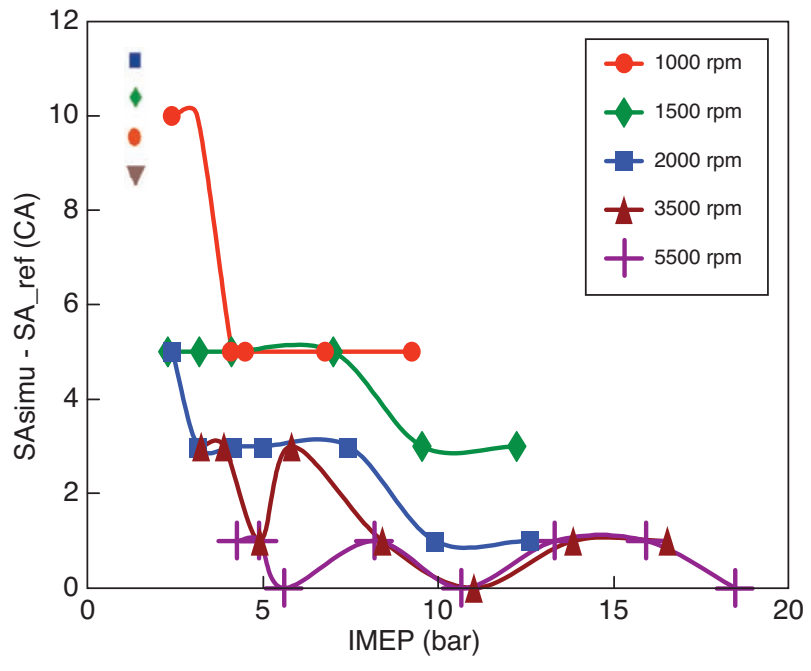

Figure 15

Errors on the optimal spark advance from simulations. Results concern only operating points not limited by knock.

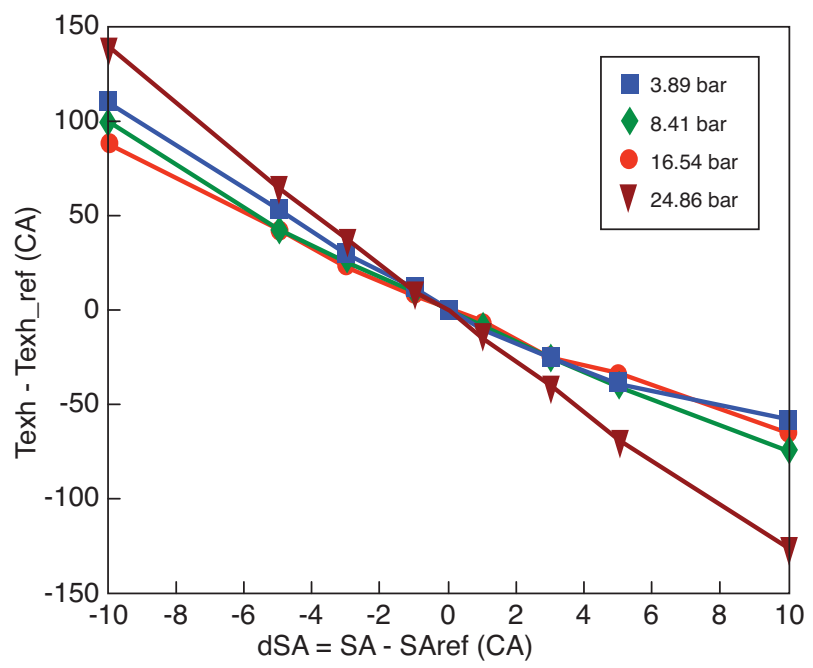

Figure 16

Spark advance variation around optimal engine settings at $3500 \mathrm{rpm}$ for different IMEP (results from simulations): differences between the exhaust temperature at the optimal spark advance (SAref) and at spark advance SA.

The exhaust temperature $T_{e x h}$ evolution is presented in Figure 18. A correct decrease is observed on the rich side, with a classical reduction of about $50 \mathrm{~K}$ for a FAR increase of 0.1 . This reduction is due to the dissociation of $\mathrm{CO}_{2}$ into $\mathrm{CO}$ and $\mathrm{O}$ in the burnt gases. The behaviour observed on the lean side is more complex. First, the temperature decreases from 1 to 0.8 because the energy released by combustion is reduced while the combustion speed does not vary much (see

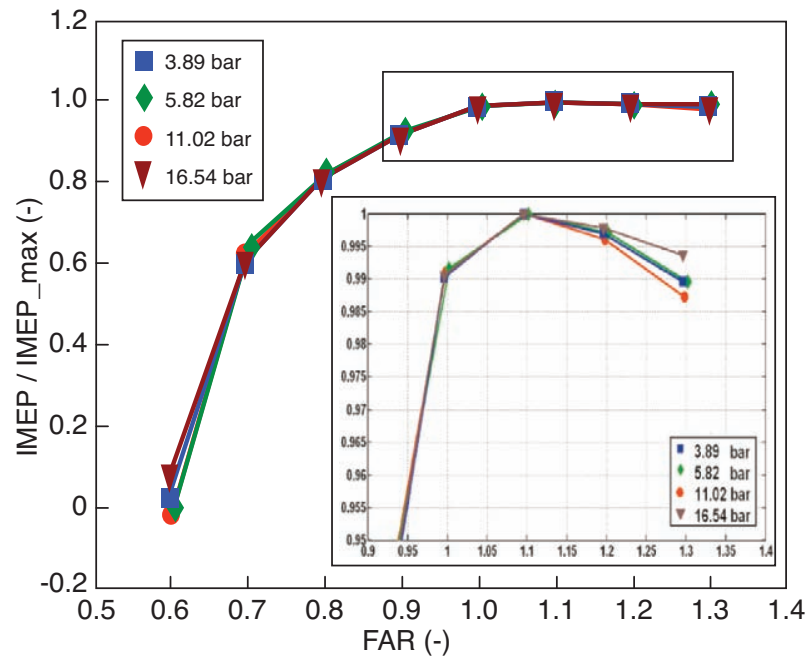

Figure 17

Fuel air equivalence ratio variation around stoichiometry at $3500 \mathrm{rpm}$ for different loads (results from simulations): differences between the current IMEP and the maximum IMEP at a given load.

the fuel burnt mass fraction evolution at IMEP $=8.41$ bar). Further, for FAR $=0.7$, the combustion speed decreases and the main part of the fuel is burnt during the expansion stroke, so that $T_{\text {exh }}$ increases. Finally, when decreasing the FAR to 0.6 , the flame speed is very slow leading to a final BMF of less than $5 \%$ at EVO and a very low level of the exhaust temperature.

\subsection{Pollutant Emissions}

Simulations of pollutant formation (CO and NOx) have been performed using a linear law for the chemical time scale which is defined as: $\tau_{\text {chem }}=10^{-2} \mathrm{~s}$ at $2500 \mathrm{~K}$ and $\tau_{\text {chem }}=$ $10^{-5} \mathrm{~s}$ at $3000 \mathrm{~K}$. Results of calculations for the 57 steady state operating points are presented in Figure 19.

Emission levels and trends are correctly predicted for most of the engine operating points. In particular, at low rpm, the NO production increases at low load and is stabilized at a value about $2500 \mathrm{ppm}$ at medium and high load. A different behaviour is observed at $5500 \mathrm{rpm}$, where a bell curve is obtained. This evolution is due to a large increase of the fuel-air equivalence ratio at high engine speed and high load. This strategy, used to limit the burnt gases temperature level in order to avoid severe mechanical and thermal damages at the exhaust, also causes an increase of $\mathrm{CO}$ emissions. For all the other operating points, $\mathrm{CO}$ levels are quite constant with the IMEP and about 0.5 to $1 \%$ for all engine speeds. This trend is similar to the experimental one, but it can be observed that 

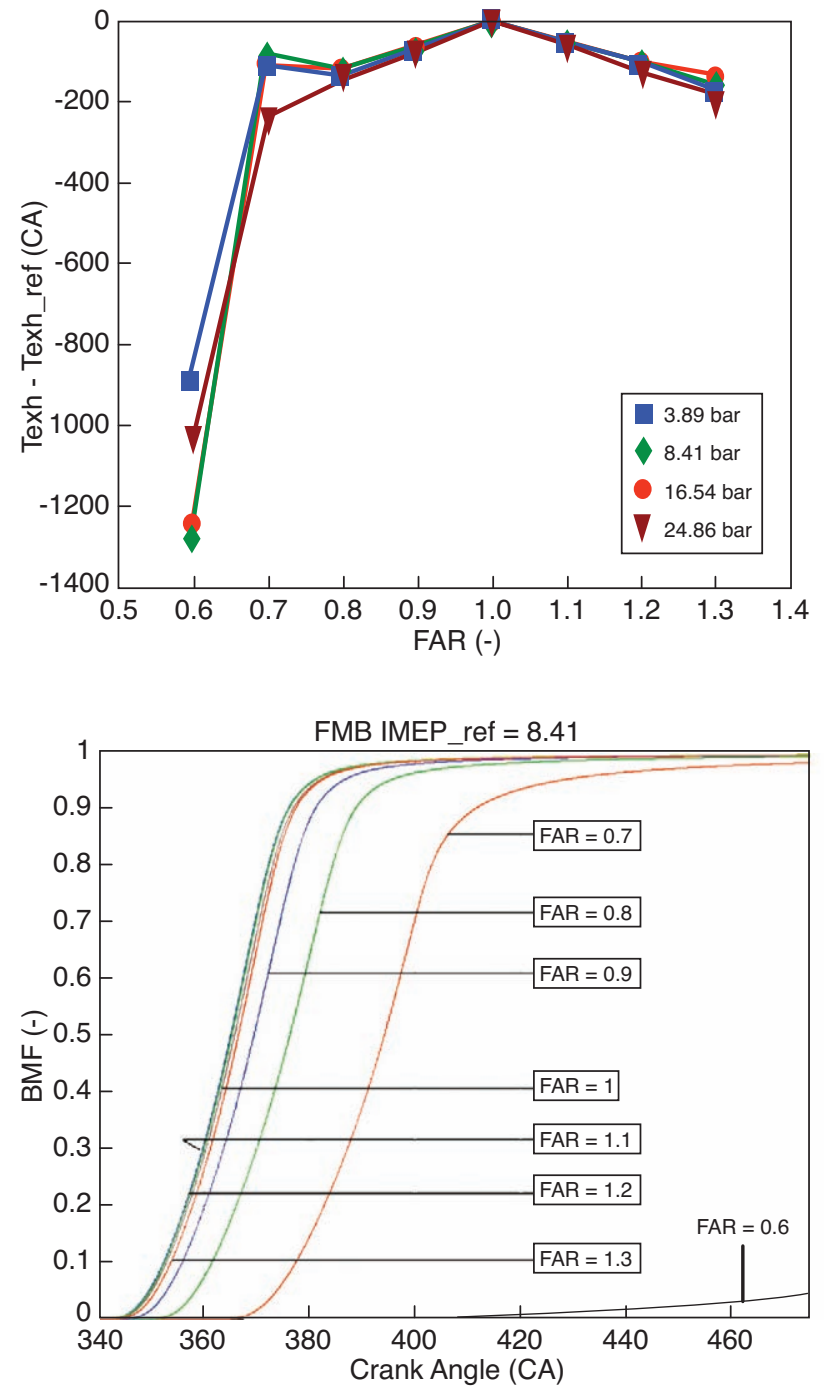

Figure 18

Fuel air equivalence ratio variation around stoichiometry at $3500 \mathrm{rpm}$ (results from simulations): top - differences between the current exhaust temperature and the exhaust temperature at stoichiometry (Texh_ref), bottom - fuel burnt mass fraction (BMF) evolution for an engine load corresponding to IMEP $=8.41$ bar at stoichiometry.

the production of $\mathrm{CO}$ is slightly underestimated, probably due to the fact that inhomogeneities of fuel and residual burnt gases distributions are not taken into account in the model.

Pollutant emissions are known to be experimentally very sensitive to the fuel-air ratio. This behaviour is well recovered when using the proposed model (Fig. 20).

Indeed, $\mathrm{CO}$ emissions begin to grow for FAR $>0.9$, because of $\mathrm{CO}_{2}$ dissociation in the burnt gases. Further, for FAR $>1$, an increasingly greater quantity of $\mathrm{CO}$ is produced in the flame front (Fig. 21), followed by a very
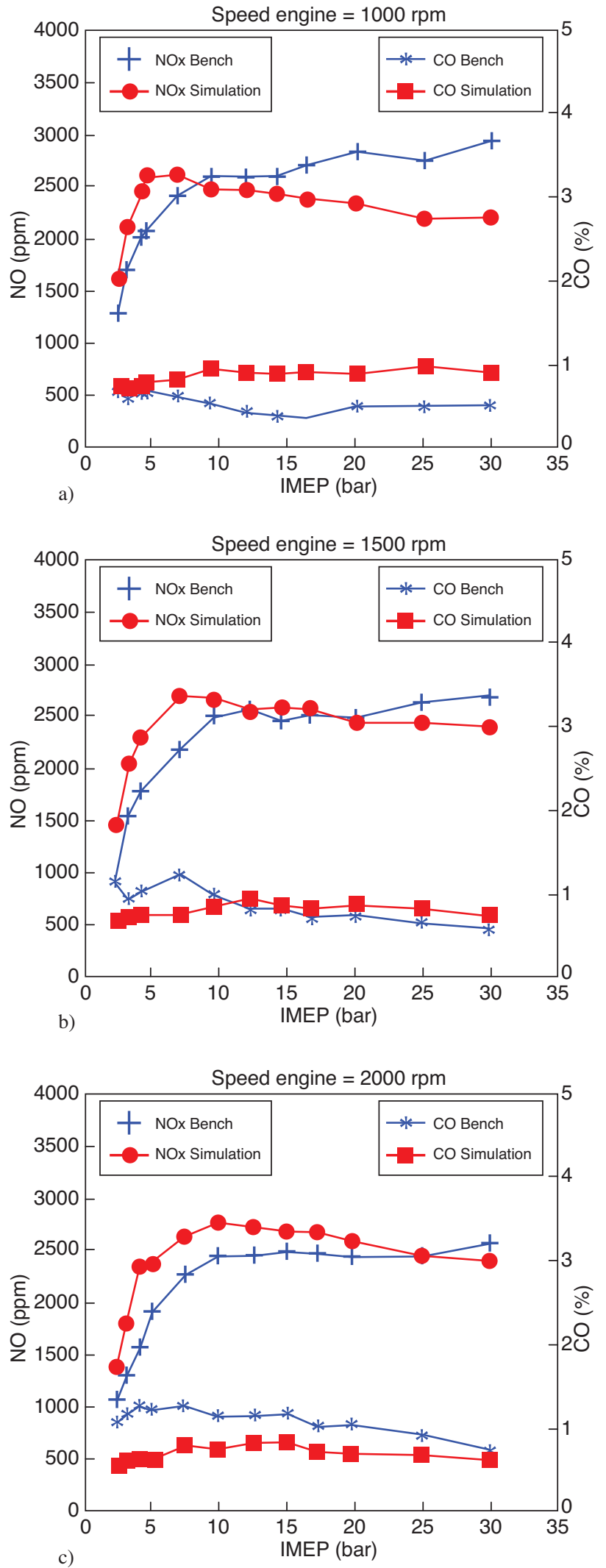

Figure 19a, b, c

Comparison of simulated and experimental pollutant emissions for the engine optimal operating points. 

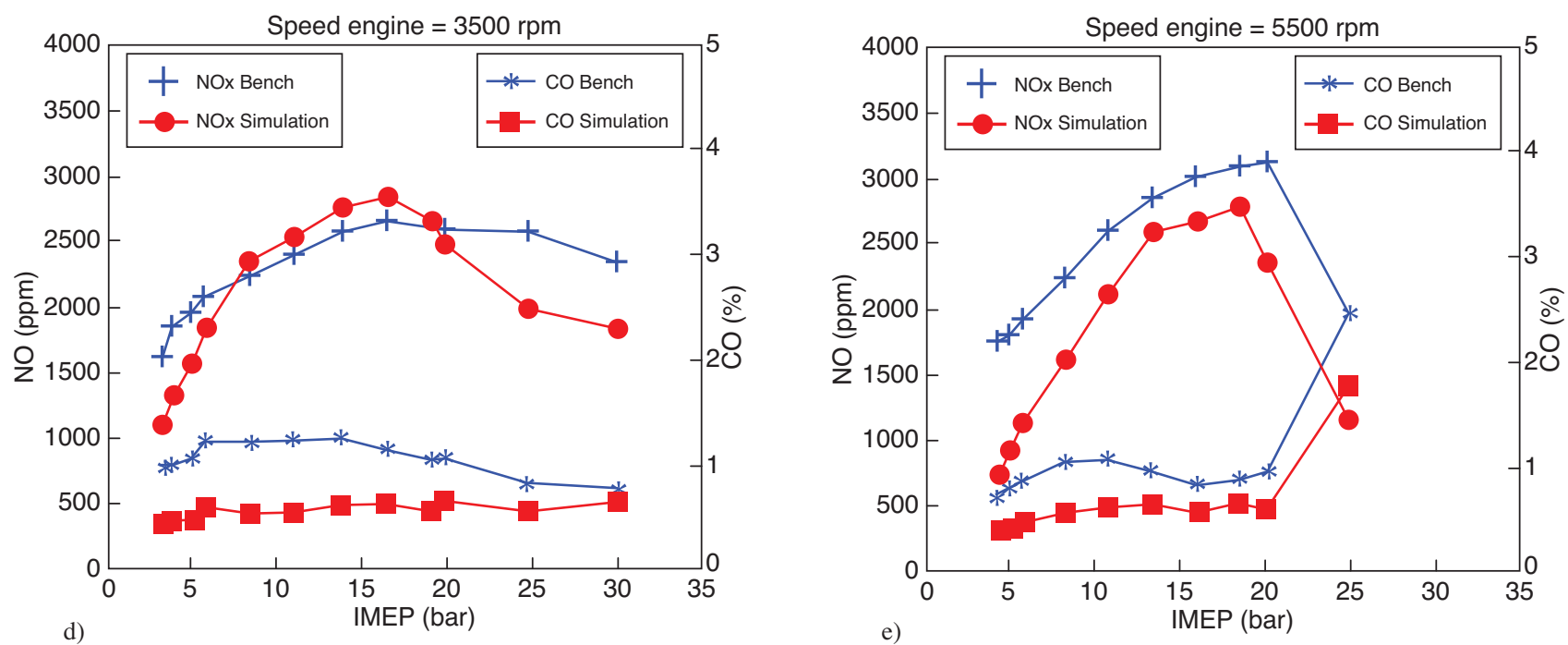

Figure 19d, e

Comparison of simulated and experimental pollutant emissions for the engine optimal operating points.
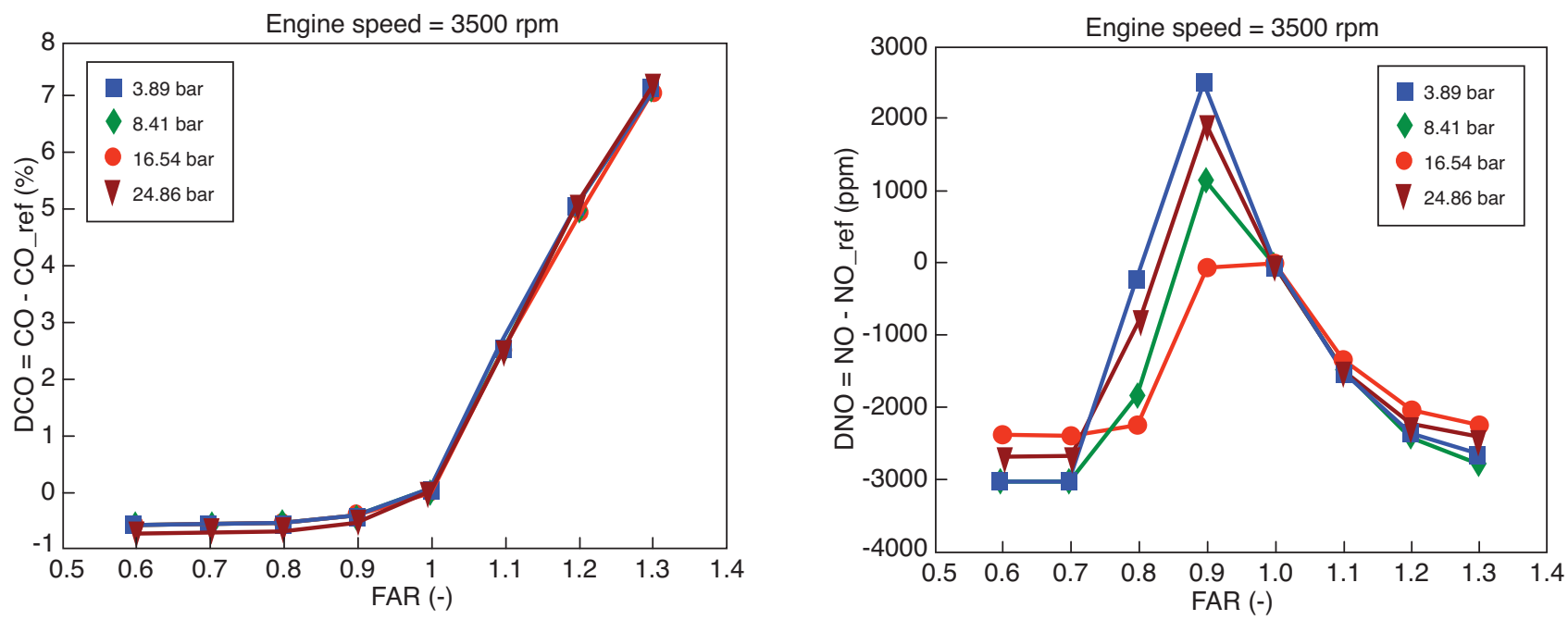

Figure 20

Fuel air equivalence ratio variation around stoichiometry at $3500 \mathrm{rpm}$ for different loads (results from simulations): top - differences between NO emissions at the current FAR and at stoichiometry (NO_ref), bottom - differences between CO emissions at the current FAR and at stoichiometry (CO_ref).

slow post-oxidation in the burnt gases leading to a significant increase of $\mathrm{CO}$ concentrations at the exhaust. The NOx evolution also shows a correct behaviour with a peak situated at $\mathrm{FAR}=0.9$, a classical value found in the literature.

\subsection{Knock}

Auto-ignition processes are mainly influenced by thermodynamic conditions in the fresh gases and by the time spent at given values of these conditions. Hence, all operating points do not favour the onset of knock to the same extent. For example, low load and high engine speed operating points have less tendencies to reach auto-ignition than high load and low engine speed points. As explained previously, operating points not affected by knock are set with a spark advance aiming at maximize the IMEP. For this purpose, the SA is tuned to obtain a maximum pressure crank angle of 373 CAD (bottom part of Fig. 22). For all other operating points, the use of an optimal spark advance would imply severe knock and the spark advance is then set to a limited value - 


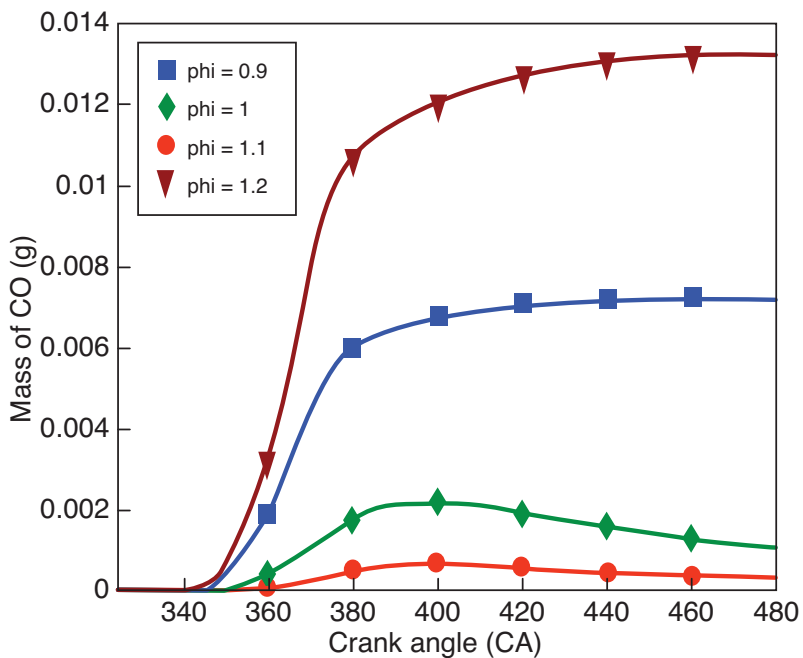

Figure 21

Evolution of the mass of $\mathrm{CO}$ in the cylinder at $3500 \mathrm{rpm}$ for a given load corresponding to IMEP $=8.41$ bars .

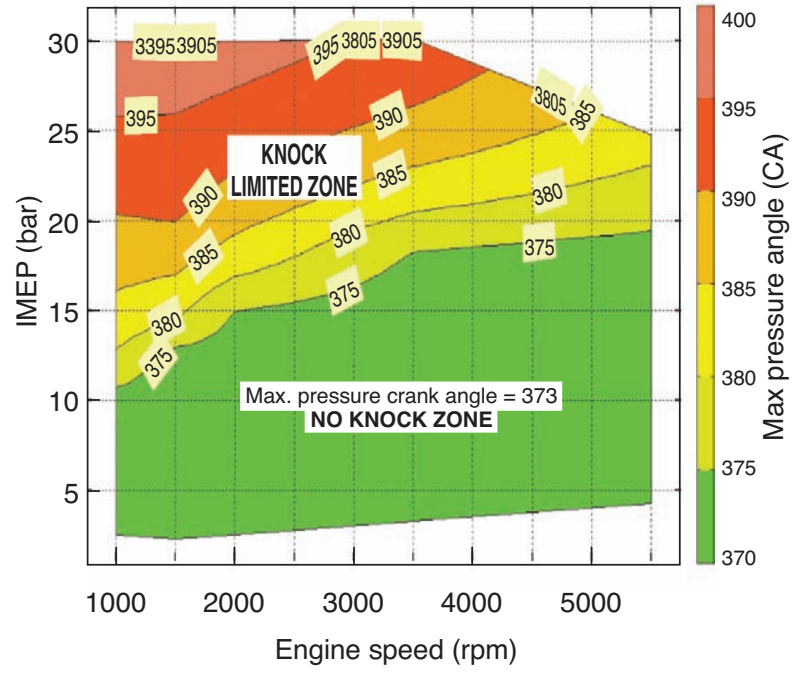

Figure 22

Maximum cylinder pressure angle as a function of the engine speed and the IMEP (load). Isolines correspond to operating points which have the same maximum pressure crank angle. called border line spark advance (BLSA) - in order to limit the knock level. Indeed, decreasing the spark advance leads to corresponding reductions in the maximum cylinder pressure (Fig. 14) and knock tendency. In this case, the crank angle at maximum pressure is higher than 375 CAD and increases with a reduction of the spark advance and consequently with the IMEP (Fig. 22). Experimentally, the BLSA is often determined by engineers for a given knock cyclic frequency which remains small and corresponds to trace knock.

In order to validate the knock model, a procedure similar to the experimental one has been followed: first simulations have been performed using engine settings provided by the bench; subsequently spark advance variations around optimal settings have been studied to check the model sensitivity to the SA. For all calculations the knock intensity constant was set to $K_{1}=67 \mathrm{rpm}^{-1}$.

Defining the dimensionless knock delay $\theta^{*}$ by the ratio between the precursor mass fraction in the fresh gases and the initial fuel mass fraction, knock is supposed to occur when $\theta^{*}=1$. Results from the simulations of the 57 steady state operating points are presented in Figure 23. As expected, $\theta^{*}$ does not reach unity at low load, especially for high engine speeds. This is coherent with Figure 23, where the no-knock zone is larger at high $N_{\text {eng }}$ values. The knock intensity, $K_{n}$ also increases correctly with the IMEP and reaches values between 0.5 and 1 , corresponding to trace knock, in the so called "knock limited zone". The limit of this zone, represented by a vertical red line and defined by an
IMEP level $\left(I^{*}\right)$ for each engine speed, is quite well predicted by the model as knock mainly appears $\left(K_{n}>0.5\right)$ for IMEP levels higher than $I^{*}$. The knock intensity is underestimated only at very high load and engine speed (for example IMEP $=20.08$ bars and $N_{\text {eng }}=5500 \mathrm{rpm}$ ). This is probably due to the fact the cylinder pressure evolution is not well reproduced for these points (Fig. 11) so that the knock delay is overestimated. In this case, the BMF at spark timing and then the knock intensity are underestimated.

One objective of a knock model is to be able to predict borderline spark advances in the "knock limited zone". Following the modelling approach chosen in this work, for each operating point of the "knock limited zone", the BLSA can be determined by varying the spark advance to reach a fixed knock intensity $K_{n}^{B L S A}$ situated between 0.5 and 1 .

Results of simulations for SA variations from -10 CAD to +10 CAD are very similar for all engine speeds and are presented in Figure 24 for $N_{\text {eng }}=2000 \mathrm{rpm}$. Expected trends are obtained: when decreasing (resp. increasing) the SA, $K_{n}$ correctly decreases (resp. increases). Moreover, a high sensitivity of the knock intensity to the SA can be observed. For example, starting from the experimental spark advance (SA_ref), a decrease of 3 to 6 CAD is sufficient to go from medium knock $\left(K_{n}>1\right)$ to no knock $\left(K_{n}<0.5\right)$. In order to compare the experimental and simulated BLSA, it is supposed that BLSA is experimentally tuned exactly at the same knock intensity level, corresponding to $K_{n}^{B L S A}=0.75$, for every points of the "knock limited zone". However, in 

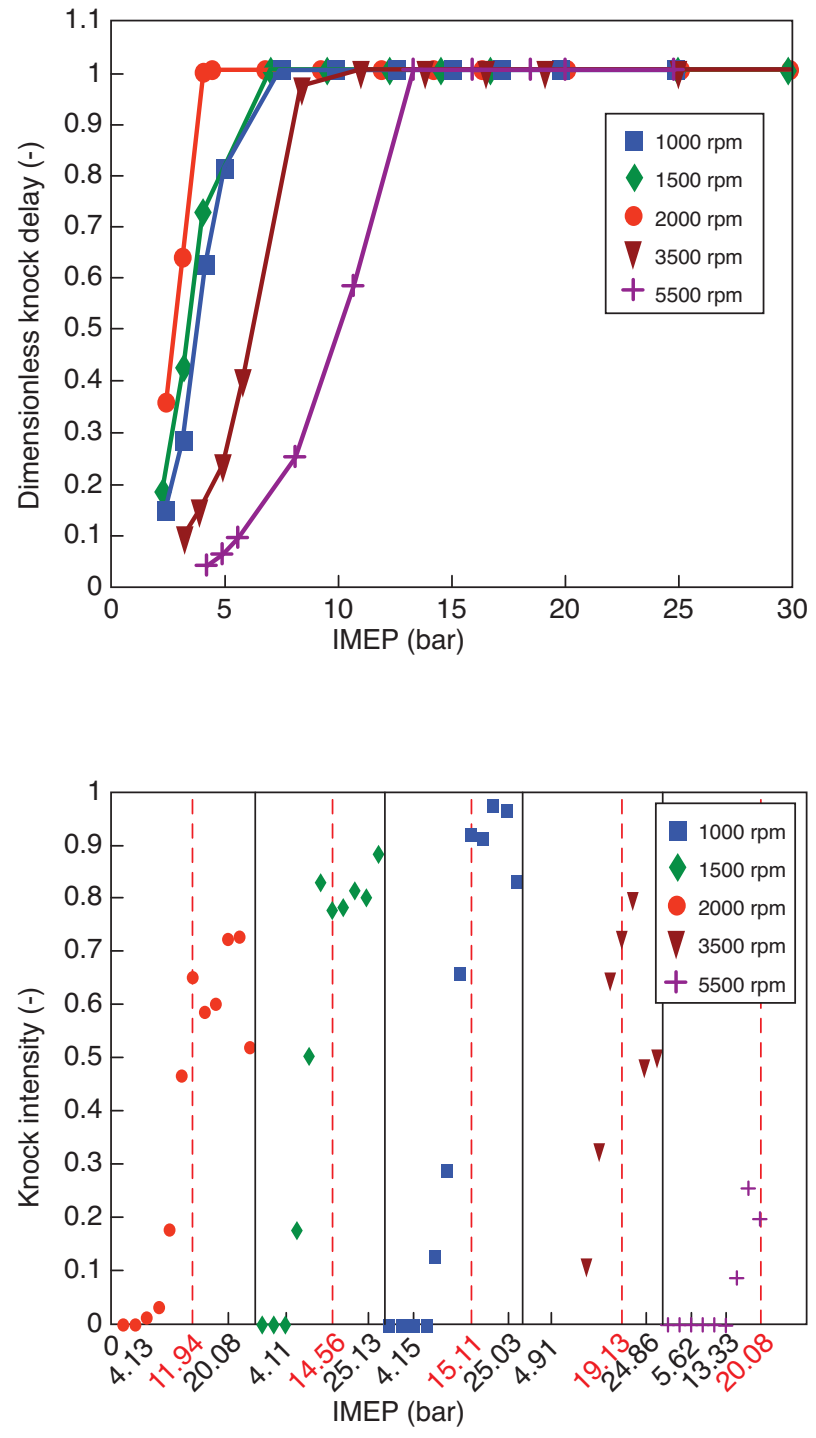

Figure 23

Results from knock simulations. Top - Dimensionless knock delay at EVO, bottom - Knock intensity at knock timing for increasing IMEP. Black lines represent the limit of an isoengine speed and red ones, the first IMEP for which knock is detected.

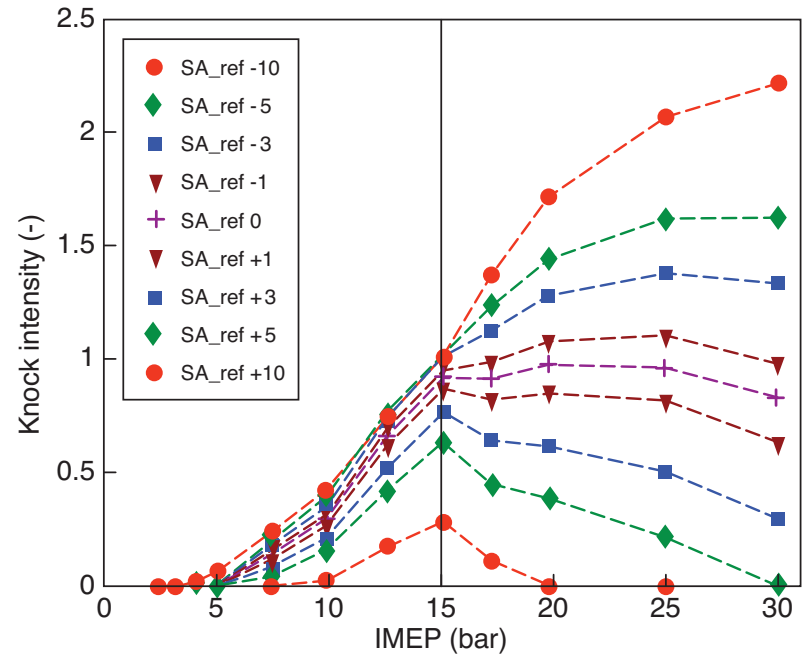

Figure 24

Evolution of the knock intensity as a function of the spark advance at $2000 \mathrm{rpm}$ for different loads (results from simulations). SA_ref corresponds to the experimental spark advance. Variations of the SA are given in CAD.

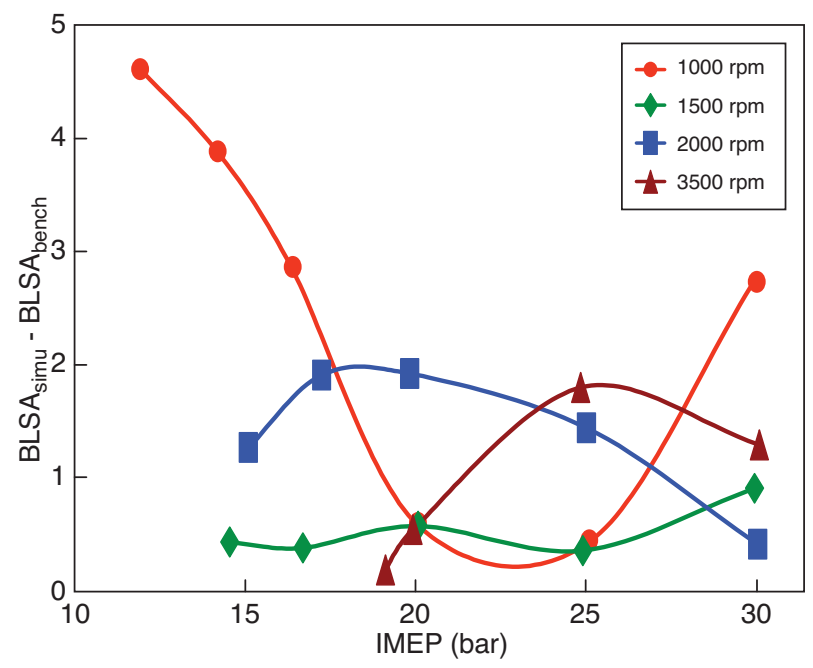

Figure 25

Errors on the knock borderline spark advance (BLSA) from simulations. reality, a margin of about +/-1 CAD can be considered. Prediction of the BLSA from simulations are shown in Figure 25. A quite good estimation is obtained for the whole knock limited zone, as the absolute error is below 2 CAD for $80 \%$ of the operating points.

In certain conditions knock can not be avoided only by decreasing the SA, as it causes a very high increase of the exhaust temperature (Fig. 16) and can lead to severe damages to the engine. In this case, the fuel-air ratio is augmented to typical values of 1.1-1.2 in order to delay the occurrence of auto-ignition. It is then important to check the behaviour of the knock model in these conditions. It is shown in Figure 26 that the knock intensity decreases of about 0.6-0.8 when increasing the fuel air ratio from 1 to 1.2 , which is in good agreement with what is usually obtained experimentally. 


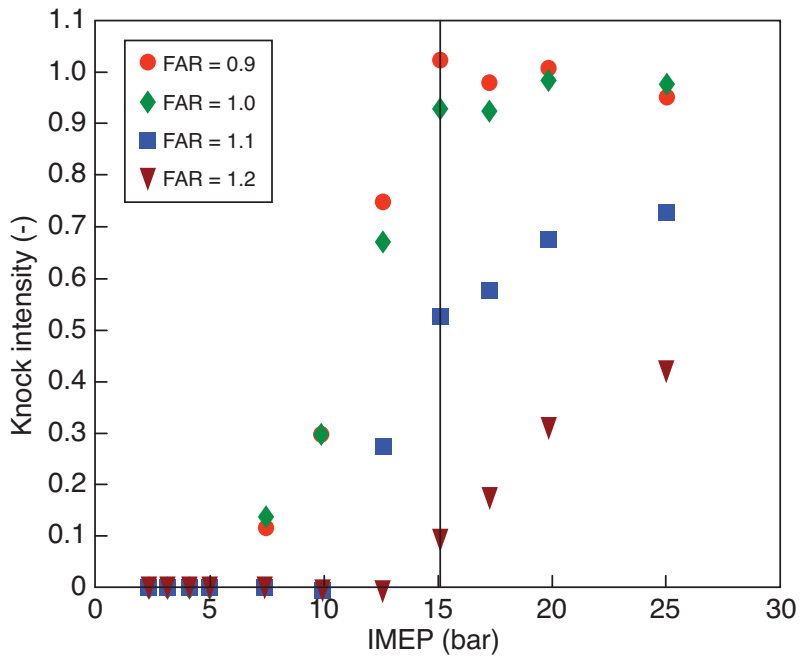

Figure 26

Evolution of the knock intensity as a function of the fuel air equivalence ratio at $2000 \mathrm{rpm}$ for different load levels (results from simulations).

\section{CONCLUSIONS}

In this paper, the latest evolutions of the CFM-1D combustion model have been presented. These evolutions concern a better description of the turbulent flame surface evolution and the prediction of knock and pollutant emissions in SI engines. For this purpose, the different transport equations of the 3D CFD E-CFM combustion model were reduced and a new set of 0D balance equations for the fresh gases enthalpy, the species and the flame wrinkling was obtained. The $0 \mathrm{D}$ combustion model was then coupled to a simple phenomenological 0D turbulence model. This turbulence model uses the integral length scale at ignition and the tumble number at IVC as initial conditions for the calculation. Pollutant emissions were then described exactly in the same way as in the 3D model: indeed, the model accounts for reactions both in the flame front and in the burnt gases zone. Finally, a knock model based on the description of the evolution of an auto-ignition precursor in the fresh gases coupled with an estimation of the knock intensity was proposed.

The CFM-1D model was then implemented in the AMESim ${ }^{\circledR}$ simulation software and used to simulate a wide range of steady state operating conditions comprising 57 points from the optimal engine map provided by experiments and variations of the spark advance and fuel air equivalence ratio around optimal engine settings. A correct description of the engine performances (IMEP, cylinder pressure curve) was obtained in terms of trends and levels for all the points of the engine map. The optimal spark advance was also cor- rectly predicted in the no knock zone. An overall good estimation of pollutant emissions was also achieved and variations of the FAR showed a correct evolution of simulated CO and NOx. Finally, the knock model was used to predict the knock limited zone frontiers as well as the border-line spark advances in this zone. A good agreement was obtained with experiments, with errors close to experimental uncertainties. In conclusion, the proposed model is able to give at the same time a good prediction of performances, pollutant emissions and knock onset on a large range of operating conditions.

Nevertheless, it should be noticed that our turbulence modelling is based on a simplified approach. Consequently, without any experimental results (cylinder pressure), the proposed model can only give an estimation of the IMEP by using default values for the integral length scale (typically about $0.5 \mathrm{~cm}$ ) and the tumble value (typically about 1 ), but can not provide a good prediction of the maximum cylinder pressure. Therefore, future work will be devoted to the reduction of a 3D turbulence model. The advantage of the CFM$1 \mathrm{D}$ is that this model is compatible with all submodels developed for the 3D E-CFM model (HC emissions, ignition, stratified combustion). Further studies will then be dedicated to the implementation of these models in the CFM-1D model.

\section{REFERENCES}

1 Tabaczynski R., Ferguson C., Radhakrishnan K. (1977) A turbulent entrainment model for spark ignition engine combustion, SAE Paper 770647.

2 Heywood J.B., Higgins J., Watts P., Tabaczynski R. (1979) Development and use of a cycle simulation to predict SI engine efficiency and Nox emissions, SAE Paper 790291.

3 Matthews R., Hall M. (1996) Combustion modeling in SI engines with a peninsula-fractal combustion model, SAE Paper 960072 .

4 D’Errico G., Ferrari G., Onorati A., Cerri T. (2002) Modelling the pollutant emissions from a SI engine, SAE Paper 2002-010006.

5 Lafossas F.-A., Colin O., Le Berr F., Menegazzi P. (2005) Application of a New 1D Combustion Model to Gasoline Transient Engine Operation, SAE Paper 2005-01-2107.

6 Emery P., Maroteaux F., Sorine M. (2003) Modeling of combustion in gasoline direct injection engines for the optimization of engine management system trough reduction of three-dimensional models to (nxone-dimensional) models, J. Fluid. Eng. 125, 520-532.

7 Colin O., Benkenida A., Angelberger C. (2003) A 3D Modeling of Mixing, Ignition and Combustion Phenomena in Highly Stratified Gasoline Engines, Oil Gas Sci. Technol. 58, 47-62.

8 Richard S., Colin O., Vermorel O., Benkenida A., Angelberger C., Veynante D. (2007) Towards large eddy simulation of combustion in spark ignition engines, Proc. Comb. Inst. 2, doi:10.1016/j.proci.2006.07.086.

9 Woschni G. (1967) Universally Applicable Equation for the Instantaneous Heat Transfer Coefficient in the Internal Combustion Engine, SAE Paper 670931, SAE Trans. 76. 
10 Metghalchi M., Keck J.C. (1982) Burning Velocities of Mixtures of Air with Methanol, iso-octane and indolene at High Pressure and Temperature, Combust. Flame 48, 191-210.

11 Baritaud T., Duclos J.-M., Fusco A. (1996) Modelling turbulent combustion and pollutant formation in stratified charge SI engine, In 26th Symp. Int. On Combustion, The Combustion Institute, pp. 2627-2635.

12 Baritaud T. (1989) Combustion and fluid dynamic measurements in a spark ignition engine - effect of thermochemistry and velocity field, turbulent flame speed, SAE Paper 892098.

13 Bozza F., Gimelli A., Merola S., Vaglieco B. (2005) Validation of a fractal combustion model through flame imaging, $S A E$ Paper 2005-01-1120.

14 Bozza F., Gimelli A. (2004) A comprehensive 1D model for the simulation of a small-size, two-stroke SI engine, SAE Paper 2004-01-0999.

15 Boger M., Veynante D., Boughanem H., Trouvé A. (1998) DNS Analysis of FSD concept for LES of turbulent premixed combustion, Proceedings of the 27th Symposium (Int.) on Combustion, The Combustion Institute, pp. 917-925.

16 Charlette F., Meneveau C., Veynante D. (2002) A power law flame wrinkling model for LES of premixed turbulent combustion, Combust. Flame 131, 159-180.

17 Bozza F., Gimelli A., Senatore A., Caraceni A. (2001) A theoretical comparison of various VVA systems for performance and emission improvements of SI engines, SAE Paper 2001-010670.

18 Le Berr F., Miche M., Le Solliec G., Lafossas F.-A. (2006) Modelling of a turbocharged SI engine with variable camshaft timing for engine control purposes, SAE Paper 2006-01-3264.

19 Blint R.J. (1986) The relationship of the laminar flame width to flame speed, Combust. Sci. Technol. 49, 79-92.

20 Poulos S.G., Heywood J.B. (1983) The effect of chamber geometry on spark ignition engine combustion, SAE Paper 830334.

21 Meintjes K., Morgan A.P. (1987) General Motors research publications, GMR-5827.

22 Heywood J.B. (1988) Internal Combustion Engine Fundamentals, McGraw-Hill, New York, pp. 450-490.
23 Lafossas F.-A., Castagne M., Dumas J.-P., Henriot S. (2002) Development and validation of a knock model in spark ignition engines using a CFD code, SAE Paper 2002-01-2701.

24 Bounaceur R., Battin-Leclerc F., Conraud V., Fournet R., Glaude P.-A. (2004) Modélisation de l'oxydation du toluène pur et en mélange avec un alcane, DCPR laboratory, Nancy, France, Research Contract CT 0308/PROG 357/IFP.

25 Karim G.A. (2004) A dimensionless criterion for predicting the onset of knock in spark ignition engines, SAE Paper 2004-011992.

26 Noda T., Hasegawa K., Kubo M., Itoh T. (2004) Development of transient knock prediction technique by using a zero-dimensional knocking simulation with chemical kinetics, SAE Paper 200401-0618.

27 D'Errico G., Lucchini T., Onorati A., Mehl M., Faravelli T., Ranzi E., Merola S., Vaglieco B.M. (2007) Development and experimental validation of a combustion model with detailed chemistry for knock predictions, SAE Paper 2007-01-0938.

28 Teraji A., Tsuda T., Noda T., Kubo M., Itoh T. (2005) Development of a novel flame propagation model (UCFM: Universal coherent flame model) for SI engines and its application to knocking prediction, SAE Paper 04-11-2005.

29 Halstead M.P., Kirsch L.J., Quinn C.P. (1977) The auto-ignition of hydrocarbon fuels at high temperatures and pressures - fitting of a mathematical model, Combust. Flame 30, 45-60.

30 Ho S.Y., Kuo T.-W. (1997) A hydrocarbon auto-ignition model for knocking combustion in SI engines, SAE Paper 971672.

31 Castagne M., Dumas J.-P., Henriot S., Lafossas F.-A. (2003) New knock localization methodology for SI engines, SAE Trans. 112, 3, 1584-1594.

32 Albrecht A., Corde G., Knop V., Boie H., Castagne M. (2005) 1D simulation of turbocharged gasoline direct injection engine for transient strategy optimization, SAE Paper 2005-01-0693.

Final manuscript received in July 2008 Published online in May 2009 